\title{
1 Different classes of Anti-Modified Protein Antibodies are induced upon 2 exposure to antigens expressing only one type of modification.
}

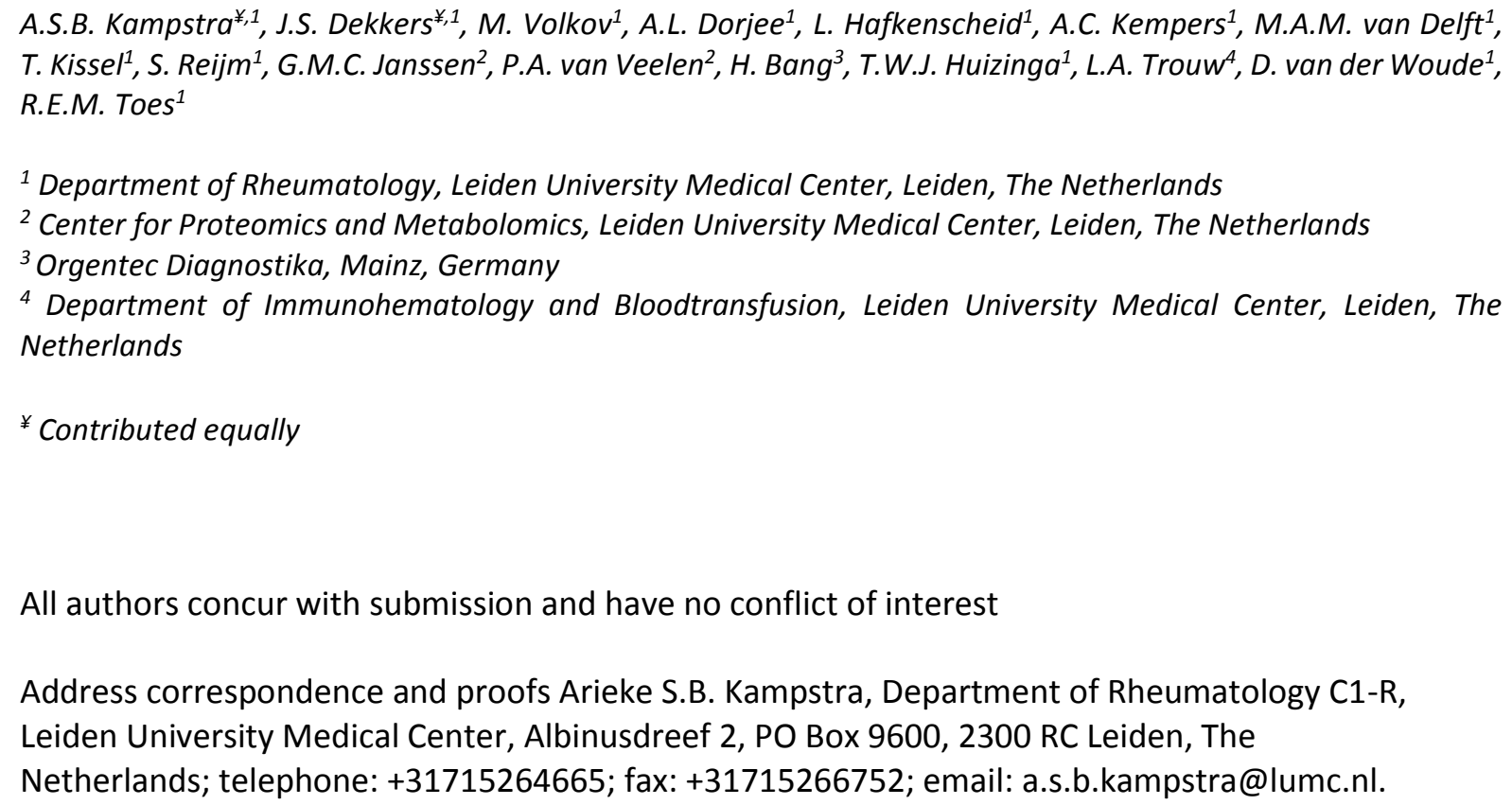

Keywords: Rheumatoid Arthritis, autoantibodies, Anti-CCP antibodies, post-translationally modified proteins, Anti-Modified Protein Antibodies

\section{Key Messages:}

What is already known?

- Antibodies targeting different Post-translational Modified proteins have been described for RA patients. Different classes of these antibodies can be present simultaneously. Nevertheless, the mechanisms behind the concurrent presence of different Anti-Modified Protein Antibody classes (AMPA) in RA are unclear.

What does this study add?

- Our data shows that, in mice, a protein expressing one particular post-translational modification can induce cross-reactive AMPA against other posttranslational modifications as well.

- Different AMPA from RA patients show similar cross-reactivity.

How might this impact on clinical practice or future developments?

- Our results indicate a "common" B cell-response from which different AMPA-responses originate, thereby providing a conceptual framework for the mutual relationship and simultaneous presence of different AMPA "classes" in RA. 


\section{ABSTRACT}

Objectives:

Autoantibodies against post-translationally modified proteins (Anti-Modified Protein Antibodies or AMPA) are a hallmark of Rheumatoid Arthritis (RA). A variety of classes of AMPAs against different modifications on proteins, such as citrullination, carbamylation and acetylation, have now been described in RA. At present, there is no conceptual framework explaining the concurrent presence or mutual relationship of different AMPA-responses in RA. Here, we aimed to gain understanding of the co-occurrence of AMPA by postulating that the AMPA-response shares a common "background" that can evolve into different classes of AMPAs.

\section{Methods:}

Mice were immunized with modified antigens and analysed for AMPA-responses. In addition, reactivity of AMPA purified from RA-patients towards differently modified antigens was determined.

\section{Results:}

Immunisation with carbamylated proteins induced AMPAs not only recognizing carbamylated proteins, but also acetylated proteins. Similarly, acetylated proteins generated (autoreactive) AMPAs against other modifications as well. Analysis of Anti-Citrullinated Protein Antibodies from RA-patients revealed that these also display reactivity to acetylated and carbamylated antigens. Similarly, anticarbamylated protein antibodies showed cross-reactivity against all three post-translational modifications.

\section{Conclusions:}

Different AMPA-responses can emerge from exposure to only a single type of modified protein. These findings indicate that different AMPA-responses can originate from a common B-cell response that diversifies into multiple distinct AMPA-responses and explain the presence of multiple AMPAs in RA, one of the hallmarks of disease. 


\section{Introduction}

The presence of Anti-Citrullinated-Protein Antibodies (ACPA) is one of the hallmarks of Rheumatoid arthritis (RA). ACPAs recognize citrullinated proteins and display an extensive citrulline-dependent cross-reactivity towards multiple citrullinated antigens [1, 2]. Interestingly, the citrullinated epitoperecognition profile expands before clinical onset of disease, possibly as a consequence of the activation of new ACPA-expressing B cells and/or progressive somatic hypermutation of individual B cell clones [3-7]. Also other Post-translationally Modified (PTM)-proteins, in particular carbamylated and acetylated proteins, have been found to be recognized by RA-autoantibodies [8]. Carbamylation and acetylation do not modify arginine, the target of citrullination, but lysine into, respectively, homocitrulline and acetyl-lysine. Homocitrulline is an amino acid resembling citrulline, but containing an additional methylene group. Anti-Carbamylated protein (anti-CarP)-antibodies are present in approximately $45 \%$ of RA-patients [9]. These antibodies can be cross-reactive to citrullinated antigens, but can also display a more restricted recognition profile directed against carbamylated proteins only. Indeed, $10-20 \%$ of ACPA-negative RA-patients are positive for anti-CarP-antibodies, indicating that these antibodies represent a different class of Anti-Modified-Protein-Antibodies $[9,10]$. Acetylation, on the other hand, is mediated by intracellular acetyltransferases. Anti-Acetylated-Protein-Antibodies (AAPAs) are present in approximately $40 \%$ of RA-patients [11] and are mainly found in ACPA-positive RA, although also ACPA-negative RA-patients can be AAPA-positive. Inhibition experiments showed limited cross-reactivity between anti-acetylated, anti-carbamylated and anti-citrullinated-protein antibodies, indicating that also AAPA represent another class of AMPA [11].

These previous observations are interesting as they indicate that AMPA, due to their concurrent presence in RA, have a commonality that is currently not understood. Here, we studied the possibility that the AMPA-response originates from a common "event" by analyzing whether exposure to one particular class of modified proteins can generate different AMPA-responses.

\section{Materials and Methods}

\section{Proteins, modifications and immunizations.}

All procedures for protein modification, mass-spectrometry and immunizations are previously described and further detailed in the supplementary materials $[9,12,13]$. Animal experiments were approved by the Ethical Committee for Animal Experimentation. All immunized mice were healthy and showed no signs of arthritis throughout the experiment.

\section{Mass spectrometry}

Procedure for the mass spectrometry analysis is described in detail in the supplementary Materials and Methods.

\section{Detection of Anti-Modified-Protein Antibodies}

For the detection of AMPAs in mice, the following Enzyme-Linked ImmunoSorbent Assay (ELISA) was performed: Modified proteins and their non-modified counterparts were coated at a concentration of $10 \mu \mathrm{g} / \mathrm{mL}$ in $0.1 \mathrm{M}$ carbonate-bicarbonate buffer $(\mathrm{pH}$ 9.6) overnight on Nunc Maxisorp plates (Thermo Scientific). The plates were blocked with PBS + 1\% BSA. The mouse sera were diluted 1:100 in RIA buffer (10mM TRIS ( $\mathrm{pH} 7.6), 350 \mathrm{mM} \mathrm{NaCl}, 1 \%$ TritonX, $0.5 \%$ Sodiumdeoxycholate, $0.1 \%$ SDS) and 
incubated overnight. Binding of mouse IgG was detected with HorseRadish Peroxidase (HRP)conjugated goat-anti-mouse IgG1 (Cat\# 1070-05, Southern Biotech) and subsequently visualized with ABTS. Washing steps were performed between each incubation with PBS $+0.05 \%$ Tween 20 . All incubations, aside from the incubations with goat-anti-mouse IgG1 and ABTS, were performed at $4^{\circ} \mathrm{C}$, the final two steps were performed at room temperature (RT). Arbitrary units were calculated using a reference serum in serial dilution. The reference serum was acquired from CaOVA-immunized or AcOVA immunized mice for the carbamylated or acetylated protein ELISA respectively. For the inhibition experiments, the sera were pre-incubated with $0-0.2 \mathrm{mg} / \mathrm{mL}$ protein for 1 hour before transferring them to the ELISA plate.

Reactivity of purified ACPA and anti-CarP antibodies, obtained from sera and synovial fluid (SF) of RA patients, was measured using modified vimentin peptides (plates and reagents were kindly provided by Orgentec), as previously described [11]. In addition, purified ACPA and anti-CarP-antibodies were tested on CCP2 and Ca-FCS respectively according to protocols previously described $[9,14,15]$.

\section{RA patients}

The material of the ACPA-positive RA patients was selected for ACPA purification based on the ACPA status and levels. The RA-patients fulfilled the EULAR/ACR 2010 classification criteria. Similar to the material from ACPA-positive patients, the material from anti-CarP-positive patients used for antiCarP-antibody isolation was derived from patients screened for anti-CarP status and levels.

\section{IgG-AMPA purification}

Specific AMPAs are isolated as has been previously described for ACPA in [16]. In short, plasma or serum samples and SF were acquired from patients. The plasma, serum and SF samples were subsequently filtered $(0.2 \mu \mathrm{M}$ filters, Millipore) before purifying AMPA with affinity chromatography (ÄKTA, GE Healthcare). Purification was performed using HiTrap streptavidin HP $1 \mathrm{ml}$ columns (GEHealthcare) coupled with biotinylated CCP2-peptides (obtained from J.W. Drijfhout, IHB LUMC) for the isolation of ACPA $[17,18]$ or in-house prepared biotinylated (Ca-)FCS for the isolation of anti-CarP antibodies. PTM-specificity was controlled by attaching a control column coated with the native version (CCP2 arginine or FCS) before the column coated with the modified version (CCP2 citrulline or Ca-FCS). Antibodies were eluted using $0.1 \mathrm{M}$ glycine hydrogen chloride $(\mathrm{HCl}) \mathrm{pH} 2.5$ and neutralized with $2 \mathrm{M}$ Tris. ACPA-lgG $\mathrm{I}_{1,2,4}$ was subsequently purified from ACPA with Prot A and Prot G HiTrapcolumns.

\section{Statistics}

Statistical tests were performed with Prism7 (Graphpad). Significance of AMPA reactivity on proteins was tested with paired t-test. Differences in titre were tested with Mann-Whitney $\mathrm{U}$ tests. Correlations were assessed with Spearman. A p-value of $<0.05$ was considered significant.

\section{Results}

\section{Cross-reactive AMPA are induced upon vaccination with one defined modified antigen.}

To analyze whether AMPA recognizing different classes of PTMs can be induced with an antigen expressing one defined modification, we immunized mice with either non-modified, carbamylated, 
citrullinated or acetylated Ovalbumin (OVA). The presence of either homocitrulline as a result of carbamylation or acetylated-lysine as a consequence of acetylation was confirmed by mass spectrometry and commercially available antibodies against either carbamylated or acetylated lysines in ELISA (Fig S1). Non-modified OVA was found to be acetylated, but not carbamylated, at the Nterminus by mass-spectrometry and therefore the latter antigen was included in all immunization experiments as additional specificity control.

To discriminate between reactivity against the PTM and protein-backbone used for immunization, we employed modified fibrinogen (Fib) as read-out. In doing so, antibodies recognizing OVA were not interfering with the detection of AMPA [13]. To control for possible baseline-reactivity towards modified proteins, sera from non-immunized mice were taken along in the ELISA experiments. Indeed, no reactivity was observed to non-modified fibrinogen or its modified counterparts in naïve animals, indicating that without immunizations, AMPA-responses are not present towards either modified fibrinogen (Fig 1A) or mouse albumin (Fig 2A)[13, 19]. Likewise, although a strong reaction against OVA was noted (data not shown), indicating proper immunization, mice immunized with non-modified OVA did not react to modified Fib (Fig 1B) nor modified mouse albumin (Fig 2B)[13]. These results indicate that neither non-modified OVA nor the adjuvant used is driving AMPA production. We were unable to detect reactivity towards citrullinated-Fib (Cit-Fib) in mice immunized with CitrullinatedOVA (Cit-Ova)(Fig 1C). As ACPA have been reported in some murine models [20-23], we additionally tested the sera on modified Myelin Basic Protein (MBP), but again were unable to detect citrullinereactivity (Fig S2). Mice immunized with carbamylated-OVA (Ca-OVA), however, displayed a strong reactivity towards $\mathrm{Ca}$-Fib, but not non-modified-Fib (Fig 1D). Remarkably, sera of mice immunized with Ca-OVA also reacted to Ac-Fib and to some extend to Cit-Fib. This reactivity was further validated using modified MBP (Fig S2). Moreover, these sera also reacted to both Ac-mouse Albumin (Ac-mAlb) and Ca-mAlb (Fig 2C), indicating that exposure to modified foreign proteins is capable of inducing a breach of tolerance towards self-antigens carrying different classes of modifications. These data are intriguing as they indicate that antibody responses induced by carbamylated-antigens are able to recognize multiple modifications, pointing to the generation of cross-reactive (auto-reactive) AMPAs induced by exposure to only one class of modified antigen.

Next, we wished to determine whether cross-reactive antibodies could also be induced by immunization with acetylated-OVA. We observed not only reactivity to Ac-Fib as expected, but also towards Ca-Fib (Fig 1E). Reactivity towards Cit-Fib was only moderately apparent. This could not be validated using Cit-MBP (Fig S2). Similar reactivity patterns were observed when modified mouse albumin was used as model auto-antigen (Fig 2D). Together, these results indicate that immunization with Ac-OVA induces (auto-)antibodies cross-reactive to acetyl-lysine and homocitrulline.

\section{Cross-reactive antibody responses harbor different PTM recognition profiles.}

To further investigate the cross-reactive nature of these AMPA-responses in more detail, we next analyzed the auto-antibody-titer through dilution of sera from immunized animals. A strong correlation and similar antibody-titers were observed towards Ac-Fib and Ca-Fib in Ca-immunized mice (Fig 3A). In contrast, the titer of antibodies recognizing Ac-Fib was considerable higher than the antibody-titer against $\mathrm{Ca}$-Fib in Ac-OVA-immunized mice (Fig 3B). These data indicate that in contrast to anti-CarP-antibodies in Ca-OVA-immunized mice, the AAPA-response in Ac-OVA-immunized mice is only partly cross-reactive to both modifications. 
The data presented on antibody-titer also predict that the AMPA-response present in Ca-OVAimmunized mice (highly cross-reactive) can be readily inhibited by both acetylated- and carbamylatedproteins, whereas the AMPA-reaction in Ac-OVA-immunized mice can only be fully inhibited by acetylated-proteins. To confirm this notion, the binding capacity towards Ca-Fib and Ac-Fib was analyzed by inhibition experiments with modified fibrinogen. Indeed, for Ca-OVA-immunized mice, antibody-reactivity towards either modified antigen could be inhibited by Ac-Fib (Fig 4A/B), whereas for Ac-OVA-immunized mice, Ac-Fib-reactivity could not be inhibited by competing with Ca-Fib (Fig $4 C / D)$. These data confirm that the AMPA-response generated by Ca-OVA-immunization is highly cross-reactive, whereas part of the antibodies induced by Ac-OVA-immunization are cross-reactive towards both modifications.

\section{Cross-reactive antibodies towards different modifications are present in RA patients.}

The data presented above show that exposure of mice to a protein carrying one defined PTM can induce cross-reactive AMPAs. To address whether also in humans, AMPA are cross-reactive towards different classes of modified antigens, we next isolated ACPA-IgG from SF or plasma of 7 RA-patients as previously described $[17,18]$. We focused on ACPA as the ACPA-response is the most prominent AMPA-response in RA. As depicted in figure $5 A$ and $B, A C P A-I g G$ were strongly enriched following isolation, whereas the flow-through contained low to no levels of ACPA-IgG (Fig S3). Next, the purified ACPA-IgG were analyzed for their reactivity towards a citrullinated, carbamylated or acetylated peptide from vimentin. In all cases, purified ACPA also showed a highly enriched reactivity towards these differently modified peptides. These data indicate that ACPA-IgG from RA patients are not only cross-reactive towards carbamylated antigens as observed previously [9], but that they can also recognize acetylated antigens. To analyze whether also anti-CarP antibodies display cross-reactivity towards different classes of PTMs, we next isolated anti-CarP antibodies from sera of 2 anti-CarPpositive patients. As shown in figure $5 \mathrm{C}$, the isolated antibodies were highly enriched for anti-CarPreactivity. Likewise, as observed for isolated ACPA, also purified anti-CarP antibodies showed strongly enriched reactivity towards the three different classes of modified antigen. Together, these data indicate that different families of human AMPA are cross-reactive towards different classes of modified antigens, including acetylated antigens.

\section{Discussion}

RA is characterized by the presence of autoantibodies against different PTMs, including citrullinated, carbamylated and acetylated proteins. As different AMPAs target different PTMs and are generally seen as distinct autoantibody families, it is intriguing that their presence often goes together in RA. At present, there is no conceptual framework explaining the concurrent presence of different AMPAresponses in RA. Here we show that exposure to a protein carrying one defined PTM can lead to crossreactive (auto)antibody-responses towards different PTMs. Interestingly, we shown that AMPA from RA patients purified with antigens carrying one particular PTM can recognise different classes of PTMs too, indicating a cross-reactive nature of these autoantibodies as well. These findings are important as they indicate that the different AMPA-responses observed in RA can, potentially, be generated by antigen(s) carrying only one particular modification. Similarly, they provide a rationale for the simultaneous manifestation of multiple AMPA-reactivities in RA. 
Given the observations that different AMPAs target different antigens and are generally seen as distinct autoantibody families, it has been intriguing to note that their presence often go together in RA. In contrast, AMPAs are less frequently present in other rheumatic diseases and their cooccurrence is rarely observed outside RA. The co-occurrence of different AMPA represent an interesting conundrum as it is unclear why, after activation of a B cell with a receptor for a particular modified protein, another $B$ cell expressing a receptor recognizing a differently modified protein would also be activated in the same subject. In general, the activation of a particular B cell will not directly influence the activation of other B cells directed against other antigens, although it has been shown in a transgenic mouse model for SLE that epitope-spreading to other antigens can occur once tolerance is broken for one self-antigen [24]. Our data indicate that exposure to a defined antigen displaying a particular class of PTM, can lead to a cross-reactive antibody-response recognizing several classes of modified antigens, conceivably explaining the co-occurrence of multiple AMPA-reactivities in RA.

It has been shown that ACPA and anti-CarP-antibodies can be cross-reactive towards citrullinated-and carbamylated antigens [9]. Citrulline and homocitrulline are highly similar in structure as they differ only one methyl-group, even though they are conversions from different amino acids. We now show that also acetylated antigens can be recognized by these antibodies. This was unexpected as acetyllysine shares less structural homology to citrulline/homocitrulline (Fig S1A). The cross-reactivity towards acetylated-antigens was even more prominent in mice because AMPA induced by Ca-OVAimmunization did not recognize citrullinated proteins, even though they are able to recognize acetylated-lysines.

The finding that exposure to e.g. an acetylated protein leads to the formation of autoantibodies against proteins carrying other classes of PTM as well, is also relevant for considerations on the breach of tolerance and induction of AMPA-responses. From our findings, it can be postulated that the inciting antigen responsible for the induction of e.g. ACPA or anti-CarP antibodies does not have to be citrullinated or carbamylated, but could be represented by, for example, an acetylated protein. Clearly, at present, we cannot conclude from our data whether a particular PTM antigen initiates AMPA-induction in RA. Nonetheless, it will be relevant to study in pre-disease samples whether a breach of tolerance towards e.g. acetylated- or carbamylated proteins precedes ACPA production or vice versa and whether this is similar in all patients or can vary from patient-to-patient.

An increasing number of studies suggest that mucosal surfaces, specifically the periodontium, the gut and the lungs, could be sites of disease initiation of RA and indicate the microbiome as an important driver of the initiation of autoimmunity. In this respect, especially protein-acetylation by bacteria might now also be incriminated in the induction of autoantibody responses against PTM proteins. Recent evidence shows that many bacterial species are able to acetylate proteins [25], including bacteria proposed as link between periodontal infection and RA [26]. Given our observation that AMPAs recognizing citrullinated and carbamylated proteins can be cross-reactive to acetylated proteins, these findings together provide a novel and stimulating angle to the notion that the microbiome contributes to the induction of autoimmunity in RA. Therefore, a logical next step is to test faecal extracts from RA patients also for the presence of acetylated bacterial proteins to obtain more insight on the possible link between the microbiome, the presence of acetylated proteins, and RA. Through the formation of acetylated proteins, disturbances of the microbiome (e.g. through infection) could lead to the formation of acetylated proteins detected by the immune system and 
thereby to the induction of AMPA-responses. In doing so, the origin of the T cell help required for the $B$ cell to undergo isotype-switching and somatic hypermutation could come from different sources. In this scenario, it is conceivable that microbe-specific $T$ cells help the B cell initially recognizing the microbe-derived modified protein. Upon further somatic hypermutation, the B cell response could be selected/start recognizing other modified proteins explaining the cross-reactive nature of AMPAs and the observation that different AMPAs often appear together in patients. Likewise, the diversification of an initial AMPA-response towards other PTMs could, potentially, also explain the observation that the HLA-Shared-Epitope (SE)-alleles are associated with ACPA-positive RA, whereas the first appearance of ACPA in healthy subjects is HLA-SE-allele independent $[27,28]$. Possibly, by diversification towards citrulline recognition, an, initially, HLA-SE-independent AMPA-reaction against e.g. acetylated proteins, could recruit new HLA-SE-restricted T cells required for further broadening of the AMPA/ACPA-response associated with disease precipitation. Thus, in this scenario, the link to the microbiome, the cross-reactive nature of AMPAs, the breach of tolerance to modified self-proteins, the HLA-Shared-Epitope-association with the "second hit", as well as the concurrent presence of AMPAs in disease can be explained.

Our study has several limitations as we did not show that also in humans the inciting antigen carrying a particular PTM will lead to the induction of a cross-reactive AMPA-response. Obviously, studies immunizing a host with a defined modified antigen, as was performed in mice, is not feasible in humans and therefore the concepts obtained from such animal-studies will be difficult to demonstrate in the human system. Nonetheless, the observation that also human AMPAs are cross-reactive to several different PTM does support such views. Furthermore, we would like to emphasize that, despite the advantages of using a controlled setting for the immunization of mice, a major pitfall of studying RA-associated antibodies in mice is the inability to induce detectable production of ACPAs with our standard immunization protocol, i.e. two subsequent immunizations in aluminium hydroxide. Consequently, the analysis of antibody cross-reactivity towards citrullinated antigens is limited and restricted to the human setting. In addition, our antibody experiments are focused on polyclonal antibody responses. Nevertheless, our inhibition studies do suggest that individual antibodies are capable of cross-recognizing multiple PTM, though isolation of monoclonal antibodies will be necessary to validate this notion. Interestingly, recent studies have shown 2 monoclonal ACPA able to interact with an acetylated histone peptide [29] as well as one able to recognize a carbamylated vimentin peptide [30].

In conclusion, our data show that induction of cross-reactive AMPA can be achieved by the encounter with a protein carrying one specific PTM and indicate that the different AMPAs present in RA could have a common "background", thereby providing novel insight into the concurrent presence of these antibodies in RA, an important hallmark of disease. 
1. van der Woude D, Rantapaa-Dahlqvist S, Ioan-Facsinay A, Onnekink C, Schwarte CM, Verpoort KN, et al. Epitope spreading of the anti-citrullinated protein antibody response occurs before disease onset and is associated with the disease course of early arthritis. Ann Rheum Dis. 2010 Aug; 69(8):1554-1561. Ge $C$, Xu B, Liang $B$, Lonnblom $E$, Lundstrom SL, Zubarev RA, et al. Structural basis of crossreactivity of anti-citrullinated protein antibodies. Arthritis Rheumatol. 2018 Aug 27.

3. van de Stadt LA, de Koning MH, van de Stadt RJ, Wolbink G, Dijkmans BA, Hamann D, et al. Development of the anti-citrullinated protein antibody repertoire prior to the onset of rheumatoid arthritis. Arthritis Rheum. 2011 Nov; 63(11):3226-3233.

4. Sokolove J, Bromberg R, Deane KD, Lahey LJ, Derber LA, Chandra PE, et al. Autoantibody epitope spreading in the pre-clinical phase predicts progression to rheumatoid arthritis. PLoS One. 2012; 7(5):e35296.

5. Verpoort KN, Jol-van der Zijde CM, Papendrecht-van der Voort EA, loan-Facsinay A, Drijfhout $\mathrm{JW}$, van Tol MJ, et al. Isotype distribution of anti-cyclic citrullinated peptide antibodies in undifferentiated arthritis and rheumatoid arthritis reflects an ongoing immune response. Arthritis Rheum. 2006 Dec; 54(12):3799-3808.

6. Titcombe PJ, Wigerblade G, Sippl N, Zhang N, Shmagel AK, Sahlstrom P, et al. Pathogenic citrulline-multispecific B cell receptor clades in rheumatoid arthritis. Arthritis Rheumatol. 2018 Jun 21.

7. Suwannalai P, van de Stadt LA, Radner H, Steiner G, El-Gabalawy HS, Zijde CM, et al. Avidity maturation of anti-citrullinated protein antibodies in rheumatoid arthritis. Arthritis Rheum. 2012 May; 64(5):1323-1328.

8. Trouw LA, Rispens T, Toes REM. Beyond citrullination: other post-translational protein modifications in rheumatoid arthritis. Nat Rev Rheumatol. 2017 Jun; 13(6):331-339.

9. Shi J, Knevel R, Suwannalai P, van der Linden MP, Janssen GM, van Veelen PA, et al. Autoantibodies recognizing carbamylated proteins are present in sera of patients with rheumatoid arthritis and predict joint damage. Proc Natl Acad Sci U S A. 2011 Oct 18; 108(42):17372-17377. 10. Chemin K, Pollastro S, James E, Ge C, Albrecht I, Herrath J, et al. A Novel HLA-DRB1*10:01Restricted T Cell Epitope From Citrullinated Type II Collagen Relevant to Rheumatoid Arthritis. Arthritis Rheumatol. 2016 May; 68(5):1124-1135.

11. Juarez M, Bang H, Hammar F, Reimer U, Dyke B, Sahbudin I, et al. Identification of novel antiacetylated vimentin antibodies in patients with early inflammatory arthritis. Ann Rheum Dis. 2016 Jun; 75(6):1099-1107.

12. Guan KL, Yu W, Lin Y, Xiong Y, Zhao S. Generation of acetyllysine antibodies and affinity enrichment of acetylated peptides. Nat Protoc. 2010 Sep; 5(9):1583-1595.

13. Dekkers JS, Verheul MK, Stoop JN, Liu B, loan-Facsinay A, van Veelen PA, et al. Breach of autoreactive $B$ cell tolerance by post-translationally modified proteins. Ann Rheum Dis. 2017 Aug; 76(8):1449-1457.

14. Kerkman PF, Rombouts Y, van der Voort El, Trouw LA, Huizinga TW, Toes RE, et al. Circulating plasmablasts/plasmacells as a source of anticitrullinated protein antibodies in patients with rheumatoid arthritis. Ann Rheum Dis. 2013 Jul; 72(7):1259-1263.

15. van Delft MAM, van Beest $S$, Kloppenburg M, Trouw LA, loan-Facsinay A. Presence of Autoantibodies in Erosive Hand Osteoarthritis and Association with Clinical Presentation. J Rheumatol. 2018 Sep 15.

16. Scherer HU, Wang J, Toes RE, van der Woude D, Koeleman CA, de Boer AR, et al. Immunoglobulin 1 (IgG1) Fc-glycosylation profiling of anti-citrullinated peptide antibodies from human serum. Proteomics Clin Appl. 2009 Jan; 3(1):106-115.

17. Rombouts Y, Willemze A, van Beers JJ, Shi J, Kerkman PF, van Toorn L, et al. Extensive glycosylation of ACPA-IgG variable domains modulates binding to citrullinated antigens in 
rheumatoid arthritis. Ann Rheum Dis. 2016 Mar; 75(3):578-585.

18. Hafkenscheid L, Bondt A, Scherer HU, Huizinga TW, Wuhrer M, Toes RE, et al. Structural Analysis of Variable Domain Glycosylation of Anti-Citrullinated Protein Antibodies in Rheumatoid Arthritis Reveals the Presence of Highly Sialylated Glycans. Mol Cell Proteomics. 2017 Feb; 16(2):278287.

19. Stoop JN, Fischer A, Hayer S, Hegen M, Huizinga TW, Steiner G, et al. Anticarbamylated protein antibodies can be detected in animal models of arthritis that require active involvement of the adaptive immune system. Ann Rheum Dis. 2015 May; 74(5):949-950.

20. Cantaert T, Teitsma C, Tak PP, Baeten D. Presence and role of anti-citrullinated protein antibodies in experimental arthritis models. Arthritis Rheum. 2013 Apr; 65(4):939-948.

21. Hill JA, Bell DA, Brintnell W, Yue D, Wehrli B, Jevnikar AM, et al. Arthritis induced by posttranslationally modified (citrullinated) fibrinogen in DR4-IE transgenic mice. J Exp Med. 2008 Apr 14; 205(4):967-979.

22. Kidd BA, Ho PP, Sharpe O, Zhao X, Tomooka BH, Kanter JL, et al. Epitope spreading to citrullinated antigens in mouse models of autoimmune arthritis and demyelination. Arthritis Res Ther. 2008; 10(5):R119.

23. Mohamed BM, Boyle NT, Schinwald A, Murer B, Ward R, Mahfoud OK, et al. Induction of protein citrullination and auto-antibodies production in murine exposed to nickel nanomaterials. Sci Rep. 2018 Jan 12; 8(1):679.

24. Degn SE, van der Poel CE, Firl DJ, Ayoglu B, Al Qureshah FA, Bajic G, et al. Clonal Evolution of Autoreactive Germinal Centers. Cell. 2017 Aug 24; 170(5):913-926 e919.

25. Ouidir T, Kentache T, Hardouin J. Protein lysine acetylation in bacteria: Current state of the art. Proteomics. 2016 Jan; 16(2):301-309.

26. Butler CA, Veith PD, Nieto MF, Dashper SG, Reynolds EC. Lysine acetylation is a common post-translational modification of key metabolic pathway enzymes of the anaerobe Porphyromonas gingivalis. J Proteomics. 2015 Oct 14; 128:352-364.

27. Hensvold AH, Magnusson PK, Joshua V, Hansson M, Israelsson L, Ferreira R, et al. Environmental and genetic factors in the development of anticitrullinated protein antibodies (ACPAs) and ACPA-positive rheumatoid arthritis: an epidemiological investigation in twins. Ann Rheum Dis. 2015 Feb; 74(2):375-380.

28. Terao C, Ohmura K, Ikari K, Kawaguchi T, Takahashi M, Setoh K, et al. Effects of smoking and shared epitope on the production of anti-citrullinated peptide antibody in a Japanese adult population. Arthritis Care Res (Hoboken). 2014 Dec; 66(12):1818-1827.

29. Lloyd KA, Wigerblad G, Sahlstrom P, Garimella MG, Chemin K, Steen J, et al. Differential ACPA Binding to Nuclear Antigens Reveals a PAD-Independent Pathway and a Distinct Subset of Acetylation Cross-Reactive Autoantibodies in Rheumatoid Arthritis. Front Immunol. 2018; 9:3033. 30. Steen J, Forsstrom B, Sahlstrom P, Odowd V, Israelsson L, Krishnamurthy A, et al. Recognition of Amino Acid Motifs, Rather Than Specific Proteins, by Human Plasma Cell-Derived Monoclonal Antibodies to Posttranslationally Modified Proteins in Rheumatoid Arthritis. Arthritis Rheumatol. 2019 Feb; 71(2):196-209. 
We thank dr. Jan Wouter Drijfhout (LUMC, Leiden) for providing the CCP2 peptide.

\section{Competing interests}

401

None declared

402

403

\section{Contributors}

404

ASBK, JSD, REMT have designed the experiments. ASBK, JSD have done the animal experiments. ASBK, JSD, MV, ALD have performed the ELISAs (murine and human). $\mathrm{LH}, \mathrm{ACK}, \mathrm{MAMvD}$ have performed the AMPA purification from RA patients. GMCJ, PAvV have done the mass spectrometry analysis of the modified antigens. ASBK, JSD, MV, HB, TWJH, LAT, DvdW, REMT were involved in critically revising the manuscript for intellectual improvement. ASBK, JSD, MV, ALD, TK, SR, LAT, DVdW, REMT have been extensively involved in the interpretation and analysis of the results. All authors have contributed to the writing and editing of the manuscript.

\section{Funding}

This work has been financially supported by the EU/EFPIA Innovative Medicines Initiative 2 Joint Undertaking RTCure grant $n^{\circ} 777357$, by ReumaNederland (13-3-401), and by Target to B! (grant $n^{\circ}$ LSHM18055-SGF). In addition, this work is part of the research programme Investment Grant NWO Medium, project $n^{\circ} 91116004$, which is (partly) financed by ZonMw).

\section{Ethical approval}

All animal experiments were approved by the Ethical Committee for Animal Experimentation of the committee at Leiden University Medical Center. Informed consent was obtained from all participants.

Data sharing

424 All available data is presented in the original paper. 
Figure 1:

Caption: Immunization with CaOVA or AcOVA induces antibody responses towards modified fibrinogen.

Antibody reactivity towards modified fibrinogen in sera derived from non-immunized (A), OVAimmunized (B), CitOVA-immunized (C), CaOVA-immunized (D) or AcOVA-immunized (E) mice was measured by ELISA. Reactivity is depicted with OD values measured at $415 \mathrm{~nm}$. For all groups, $\mathrm{n}=6$. Representative data from two experiments is shown. OVA, ovalbumin; Cit, citrullinated; Ca, carbamylated; Ac, acetylated; Fib, fibrinogen; OD, optical density.

Figure 2:

Caption: Break of tolerance towards modified self-proteins in CaOVA- and AcOVA-immunized mice.

Reactivity towards carbamylated and acetylated mouse albumin was tested by ELISA (A) with sera derived from non-immunized (A), OVA- (B), CaOVA- (C) and AcOVA-immunized (D) mice. Results show representative data from two immunization experiments. $p<0,05$ depicts significance. OVA, ovalbumin; Ca, carbamylated; Ac, acetylated; AU, arbritrary units; $p$, p-value.

Figure 3:

Caption: Antibody titers and avidity in sera of CaOVA- and AcOVA-immunized mice.

Antibody titers as measured by ELISA on CaFib and AcFib for CaOVA- (A) and AcOVA-immunized (B) mice. IC50 depicts the dilution at which half of the max reactivity is present. Representative data from two experiments is shown. Representative data from two immunization experiments is shown. $\mathrm{Ca}$, carbamylation; Ac, acetylation; OVA, ovalbumin; Fib, fibrinogen; IC50, inhibitory concentration at 50\%; $\mathrm{OD}$, optical density.

Figure 4:

Caption: Inhibition of antibody binding by pre-incubation of mouse sera with modified fibrinogen.

Cross-reactivity of antibodies is studied by assessment of the inhibitory capacity of pre-incubating sera with modified fibrinogen. Sera from CaOVA-immunized mice was pre-incubated with varying concentrations of modified fibrinogen before testing the antibody reactivity on CaFib (A) or AcFib (B). Sera from AcOVA-immunized mice was pre-incubated with varying concentrations of modified fibrinogen before testing the antibody reactivity on $\mathrm{CaFib}$ (C) or AcFib (D). Results show representative data of two experiments. OVA, ovalbumin; Fib, fibrinogen; Ca, carbamylated; Ac, acetylated; OD, 
459 Figure 5:

460 Caption: Cross-reactivity of purified human ACPA or anti-CarP antibodies towards modified 461 vimentin peptides.

462 ACPA and anti-CarP antibodies were isolated from RA patients. ACPA from synovial fluid $(A, n=4)$ and $463 \operatorname{serum}(B, n=3)$ from patients were tested on CCP2 and modified vimentin peptides. Anti-CarP 464 antibodies from serum of RA patients $(C, n=2)$ were tested on Ca-FCS and modified vimentin peptides. 465 Reactivity is depicted as arbitrary units per $\mathrm{mg}$ IgG and calculated based on standards. CCP2, cyclic 466 citrullinated peptide; CArgP2, cyclic arginine control peptide; Vim, vimentin peptide; Cit, citrullinated; 467 Arg, arginine control; AcLys, acetylated lysine; Lys, lysine control; hCit, homocitrulline (carbamylated); 468 FCS, fecal calf serum; $\mathrm{Ca}$, carbamylated; $\mathrm{AU} / \mathrm{mg}$ IgG, arbitrary units per milligram immunoglobulin $\mathrm{G}$. 
A

Non-immunised mice

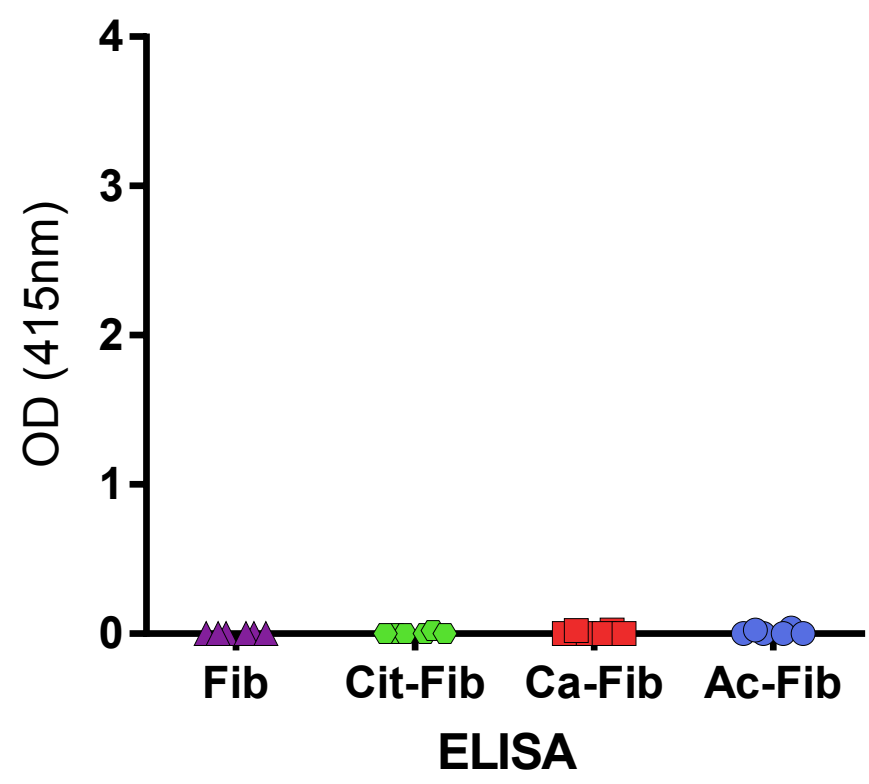

C

Cit-OVA-immunised mice

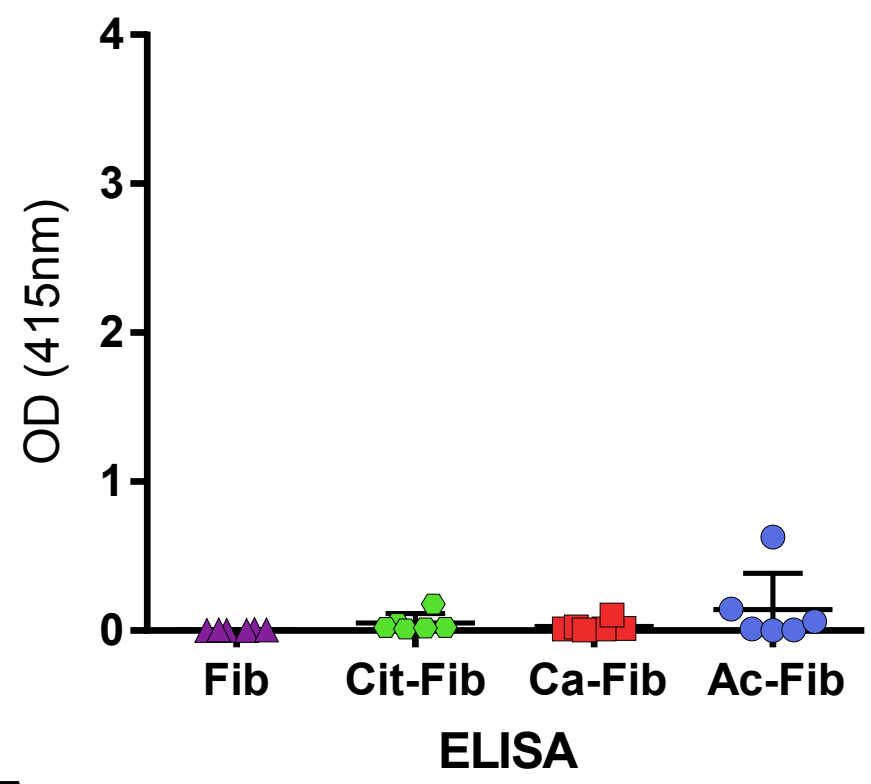

$\mathbf{E}$

Ac-OVA-immunised mice

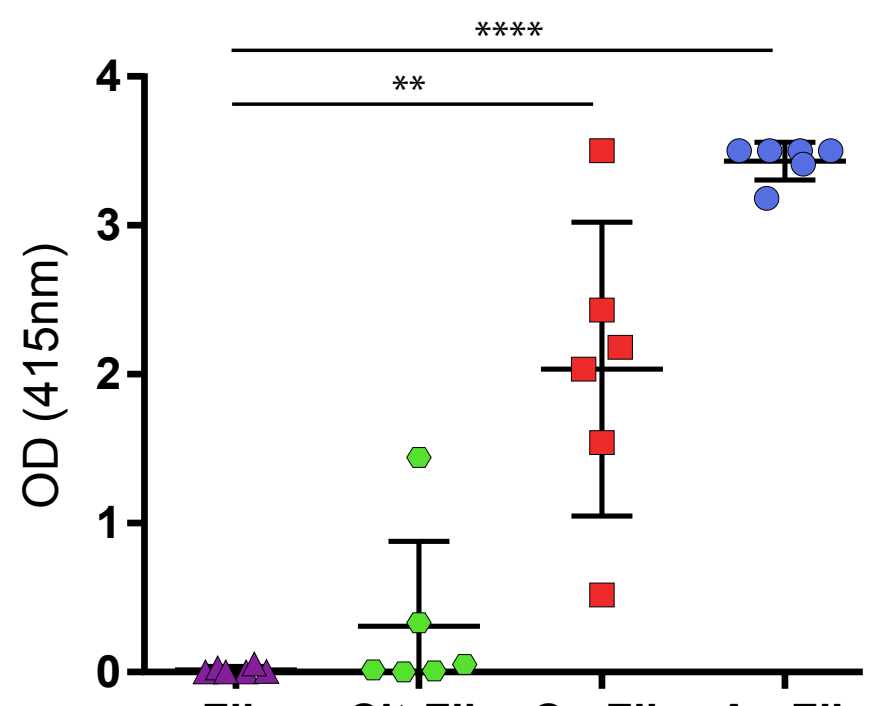

Fib Cit-Fib Ca-Fib Ac-Fib

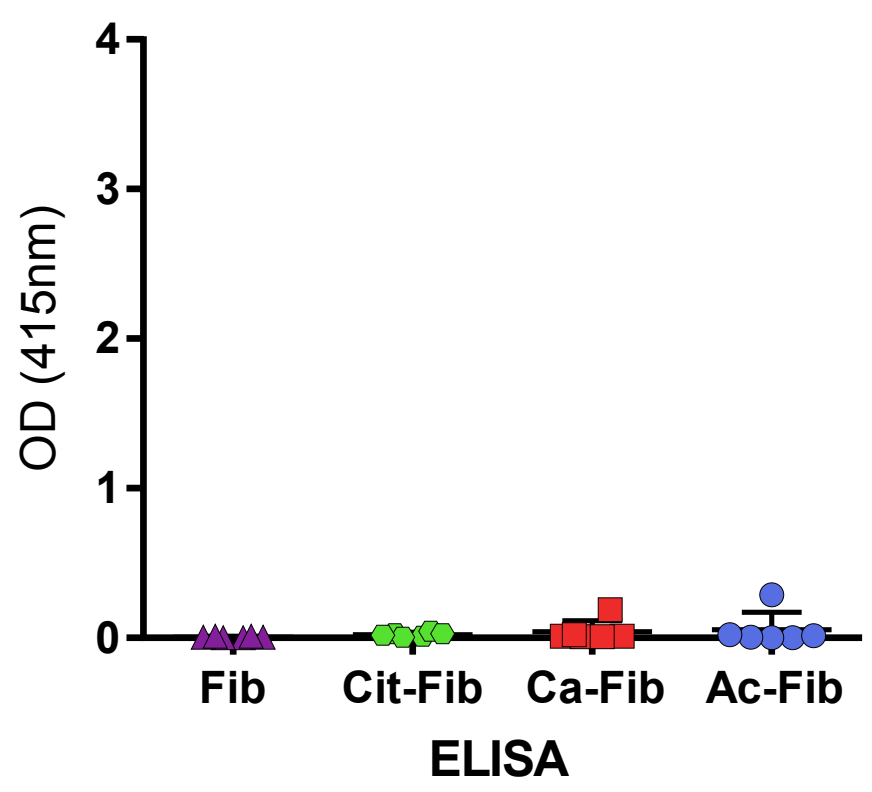

D Ca-OVA-immunised mice

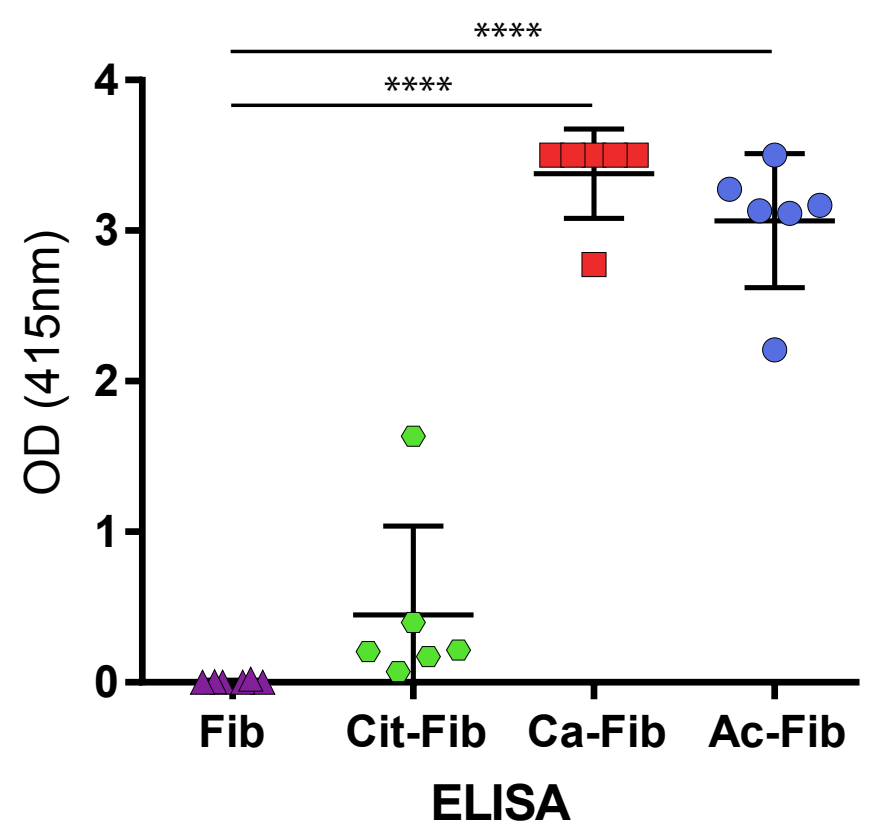


A

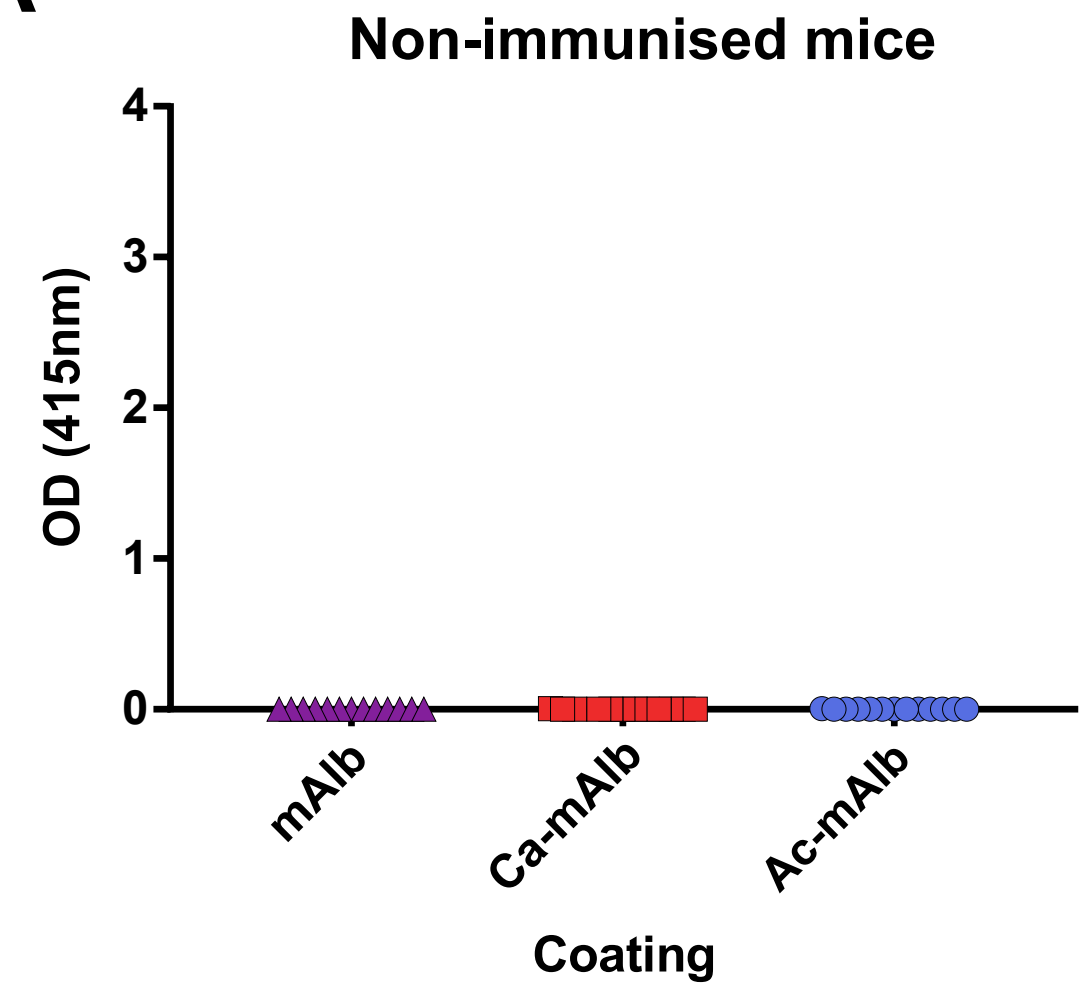

C

Ca-OVA-immunised mice

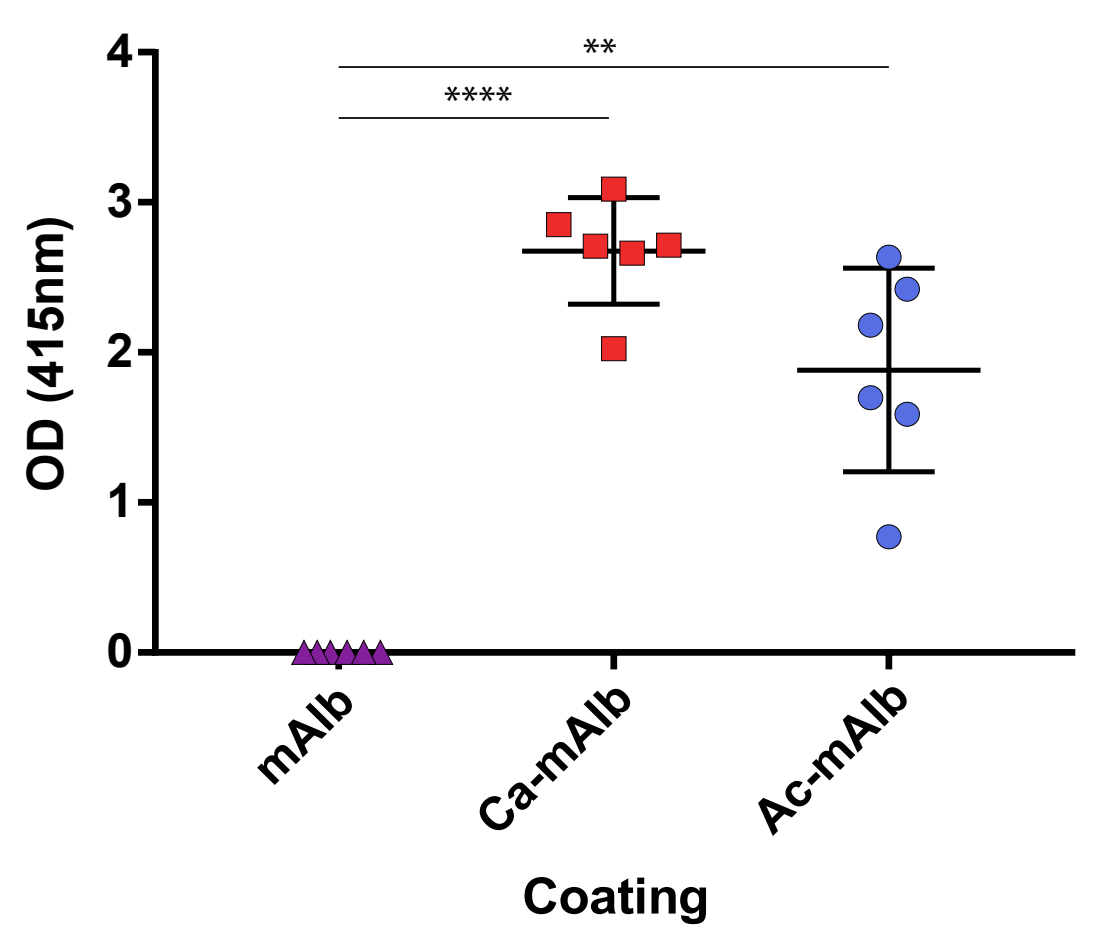

OVA-immunised mice

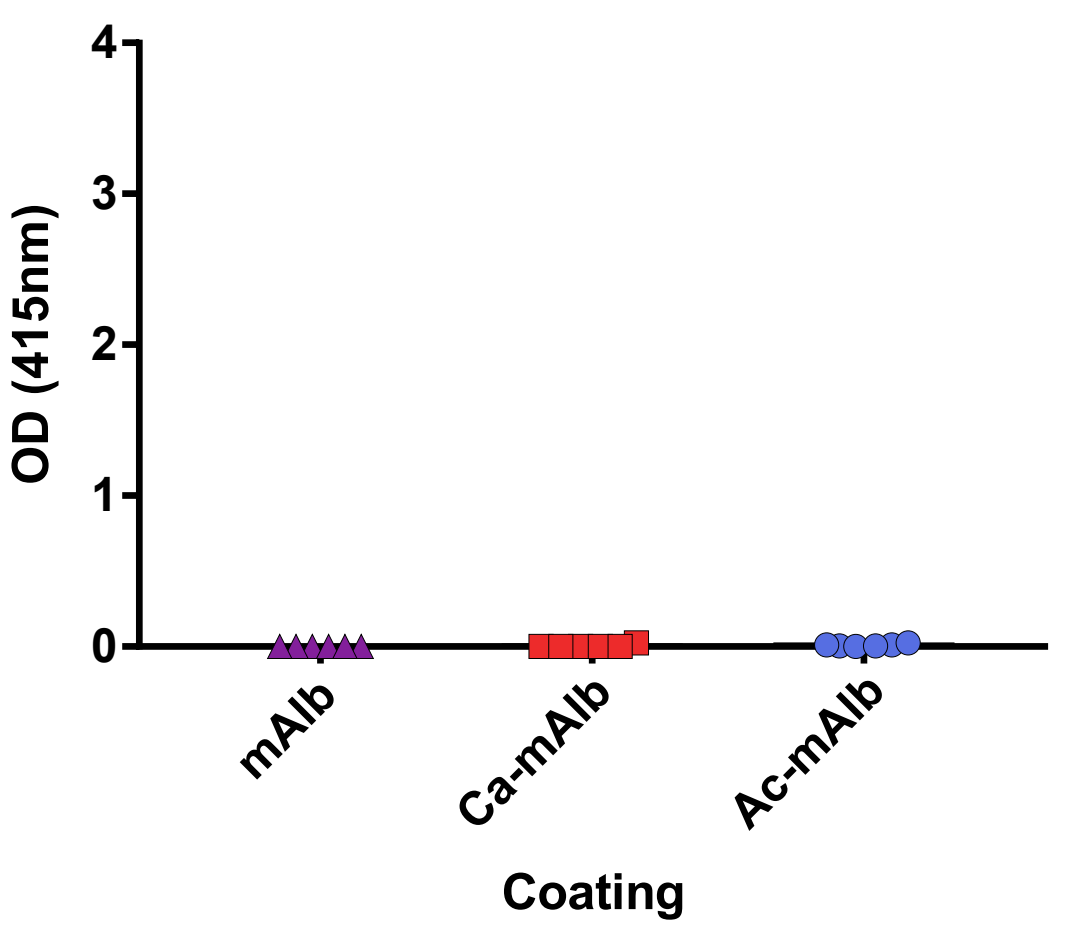

D

Ac-OVA-immunised mice

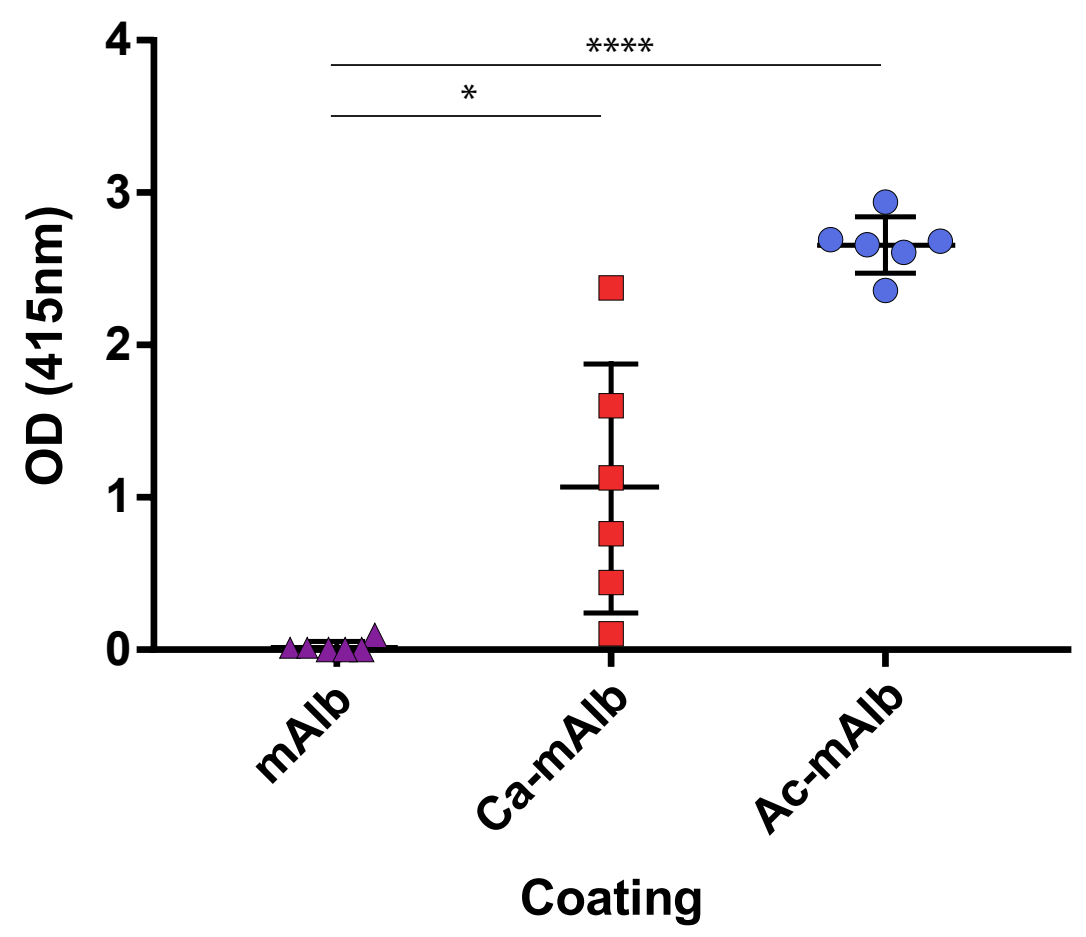


Ca-OVA-immunised mice

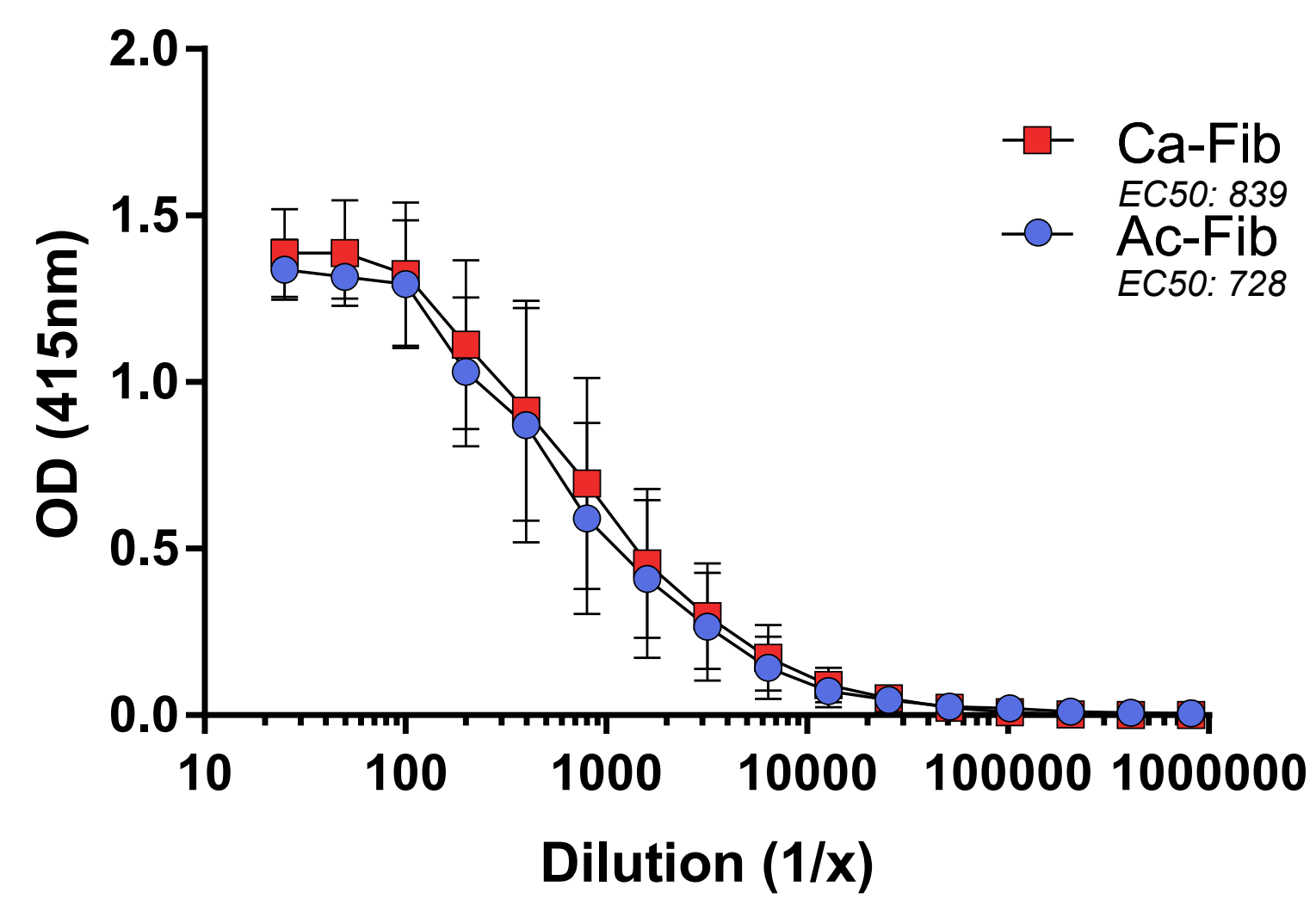

Ac-OVA-immunised mice

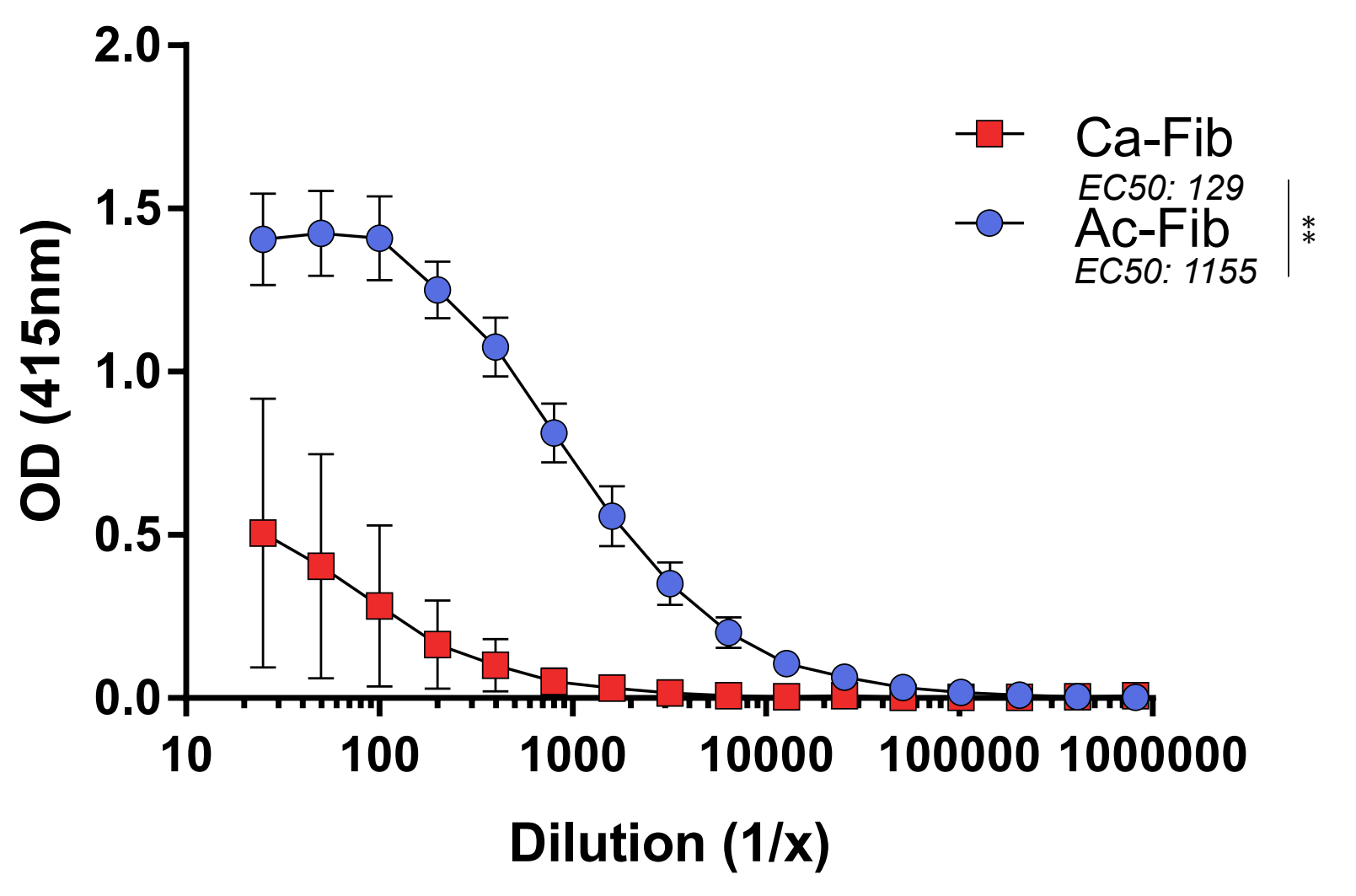




\section{Ca-OVA-immunised mice}

A

Carbamylated

Fibrinogen reactivity

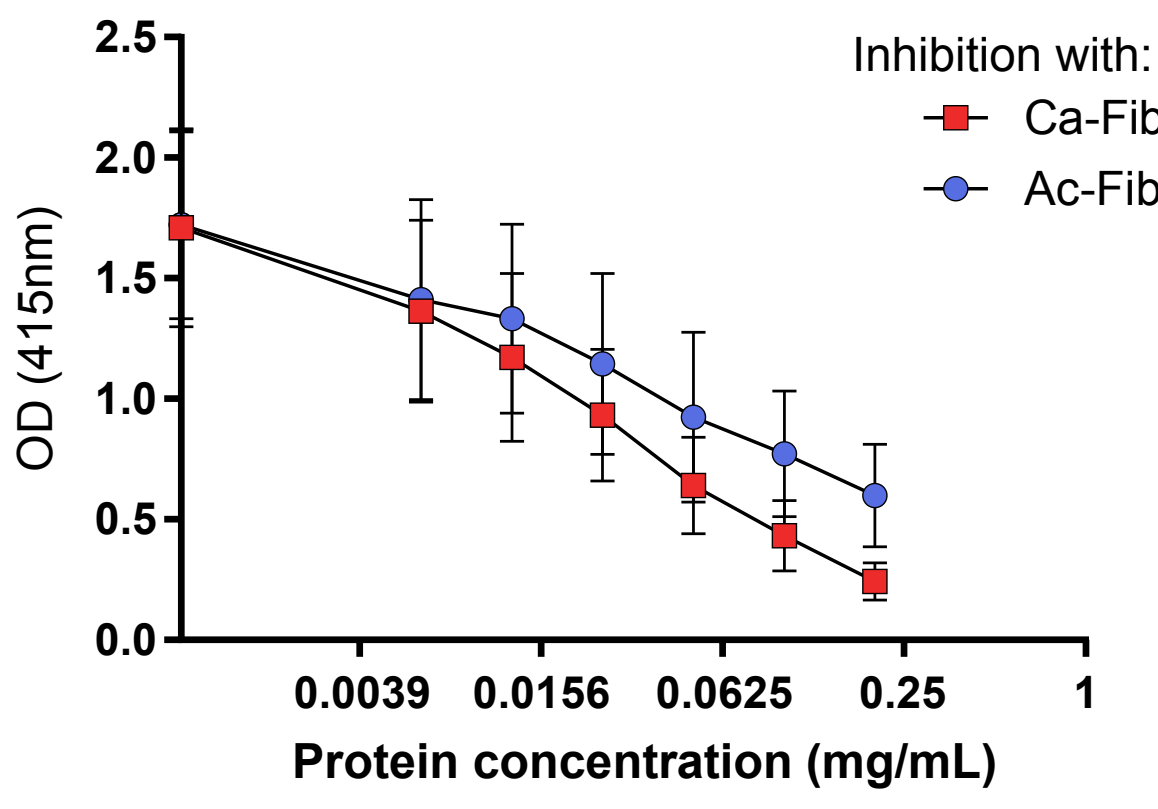

\section{Ac-OVA-immunised mice}

C

Carbamylated

Fibrinogen reactivity

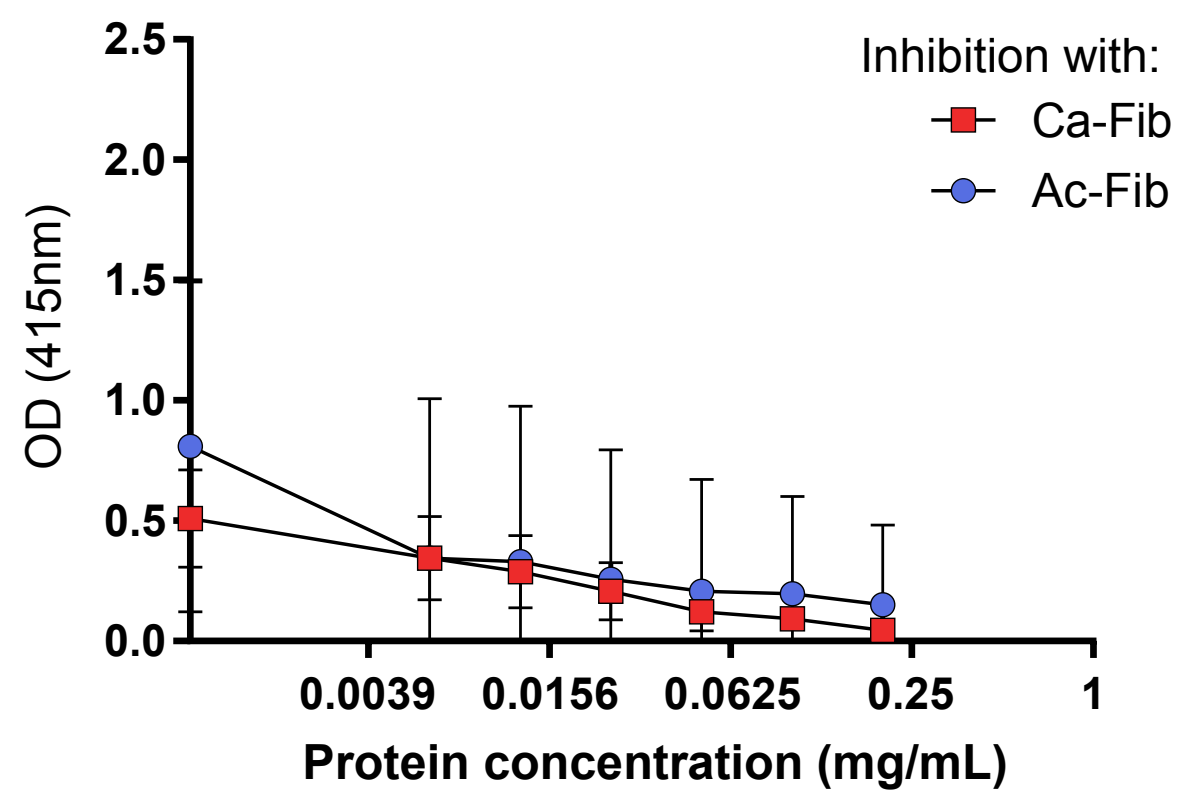

B

Acetylated

Fibrinogen reactivity

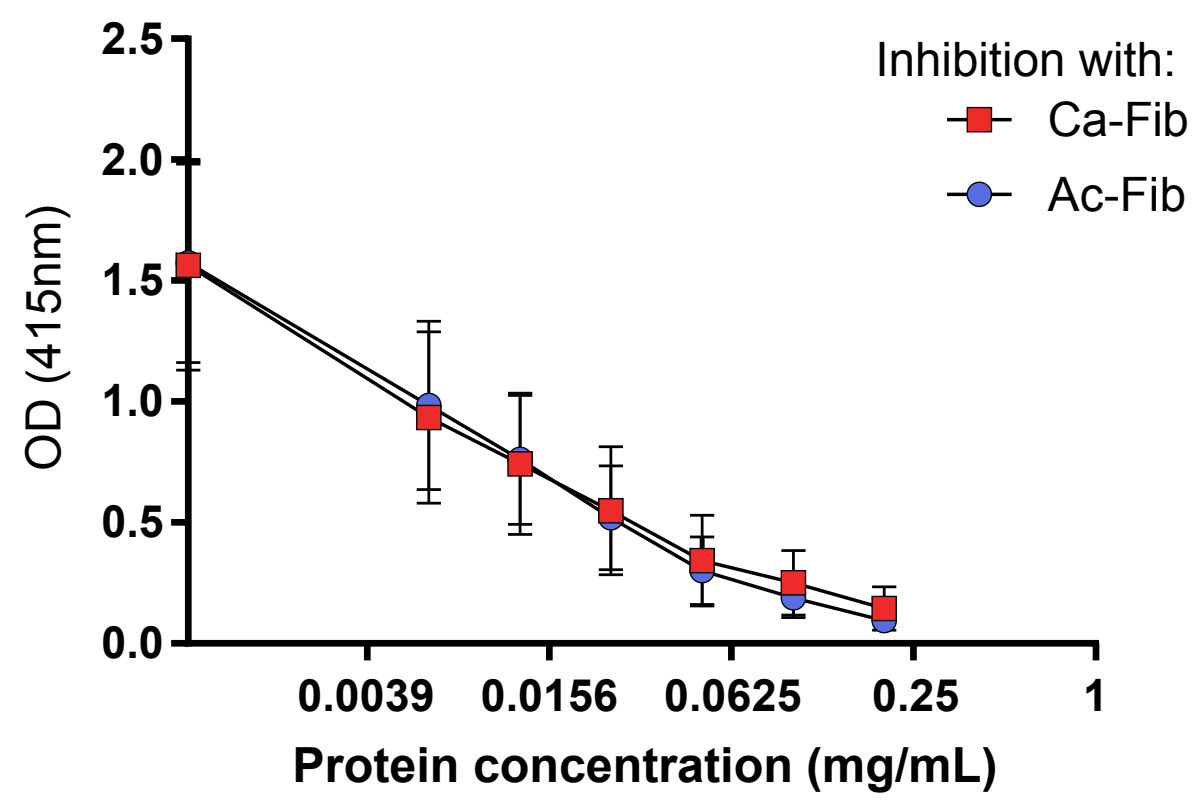

D Acetylated Fibrinogen reactivity

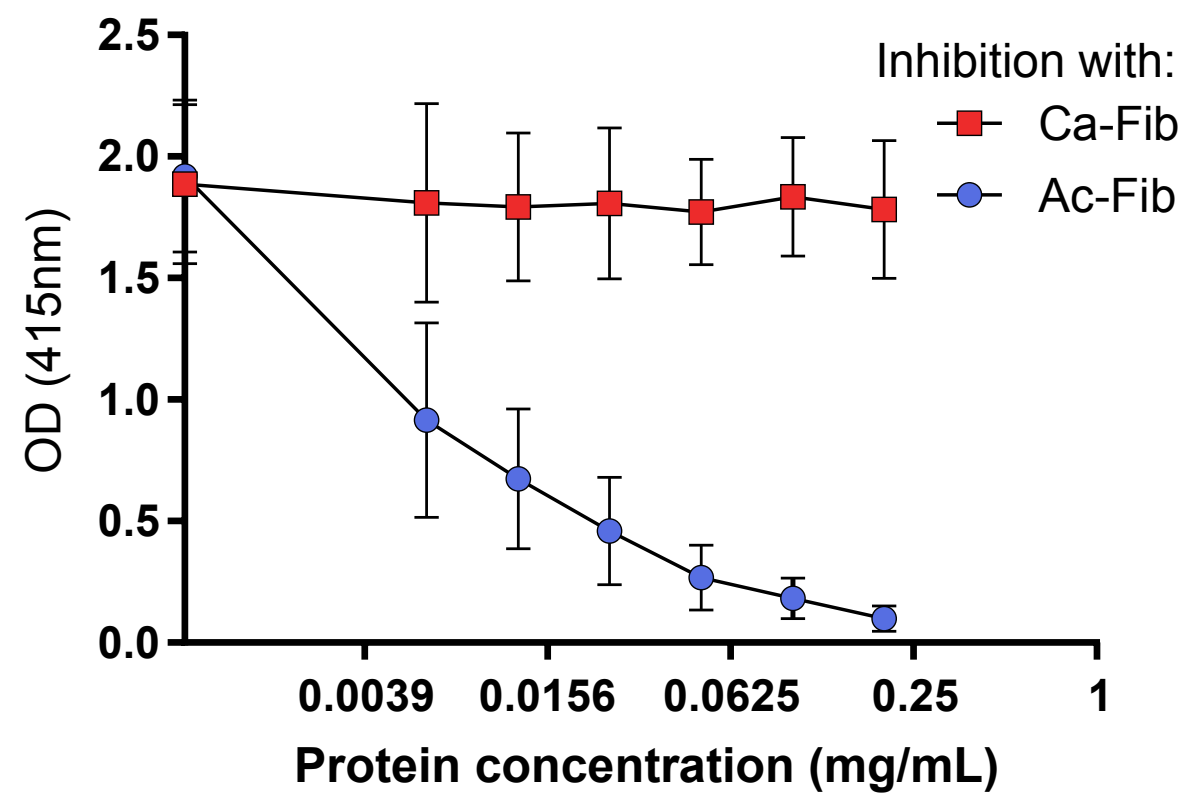




\section{A}

RA1
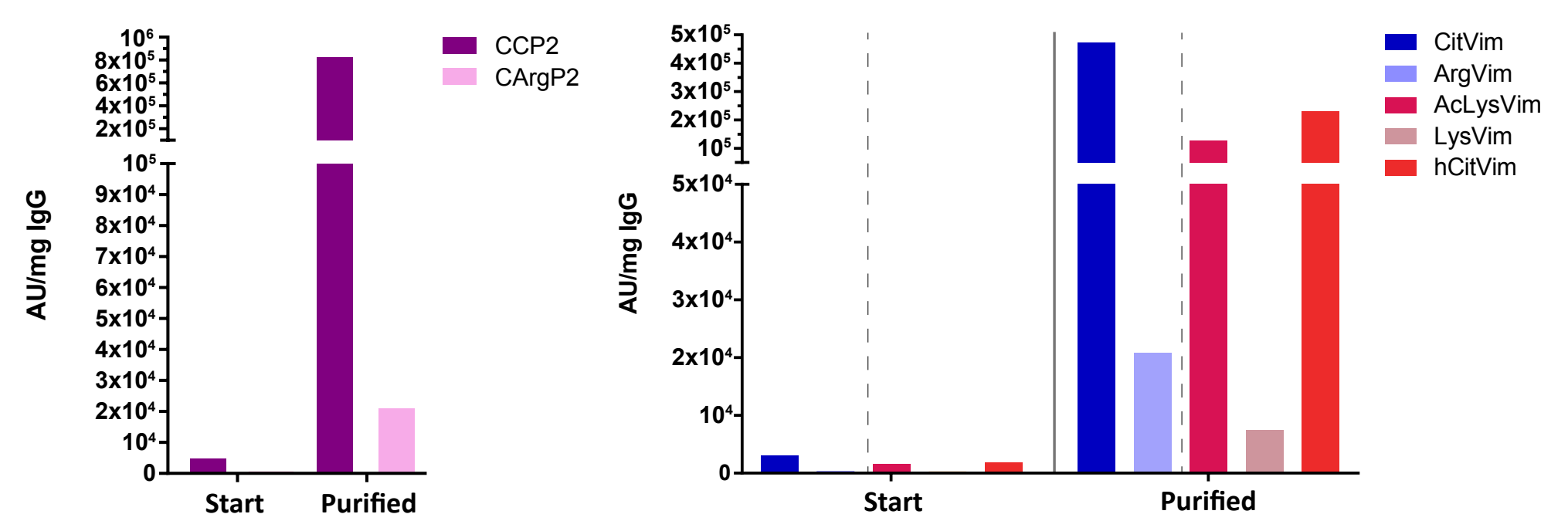

RA2

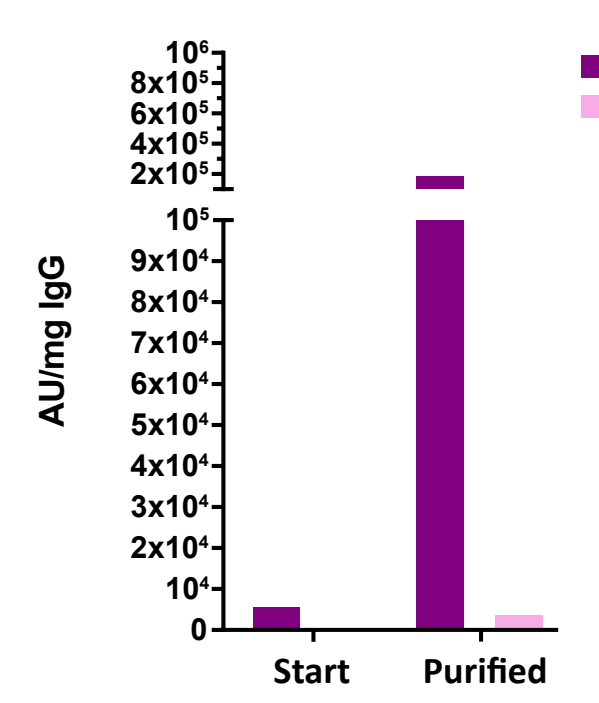

$$
\text { RA3 }
$$
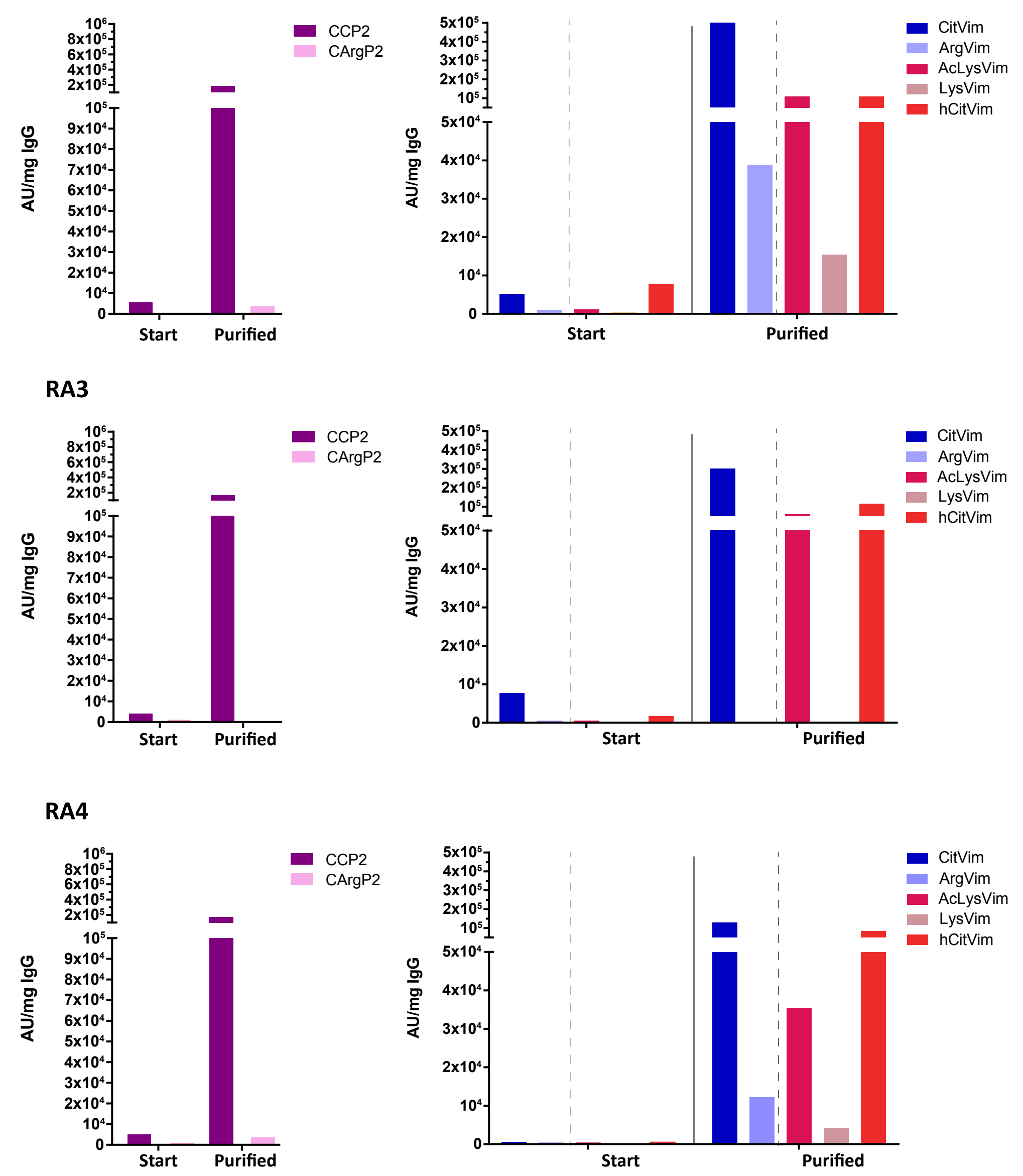

RA5
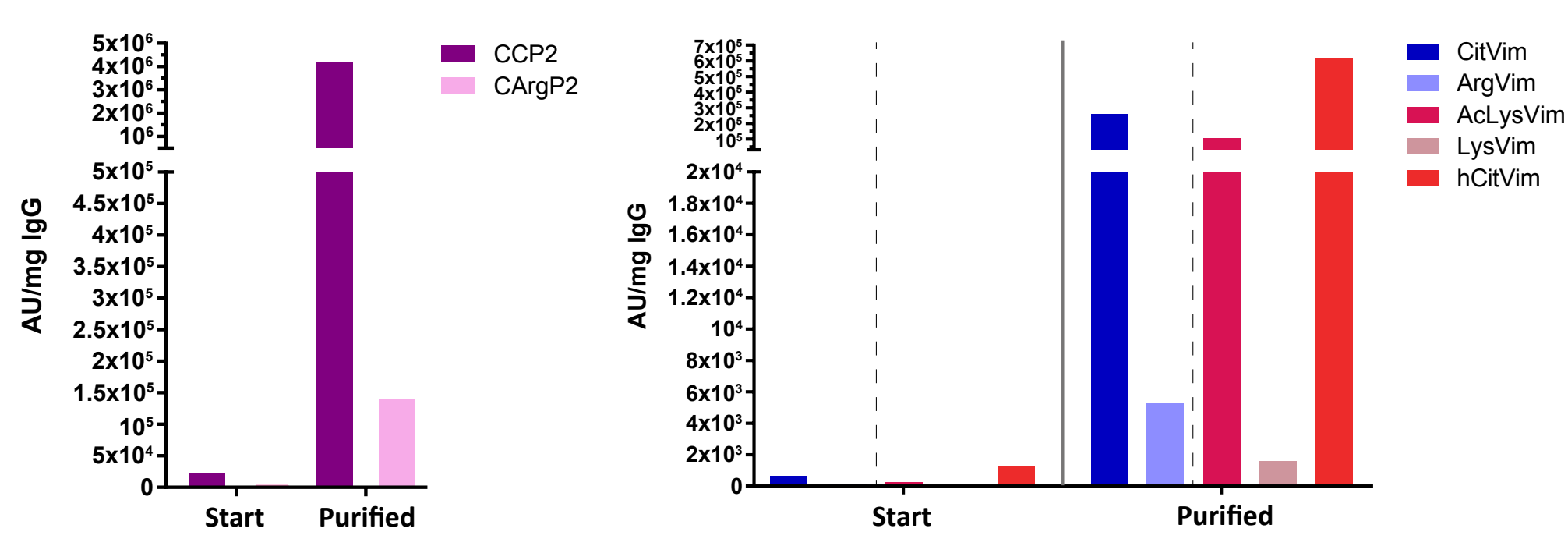

RA6
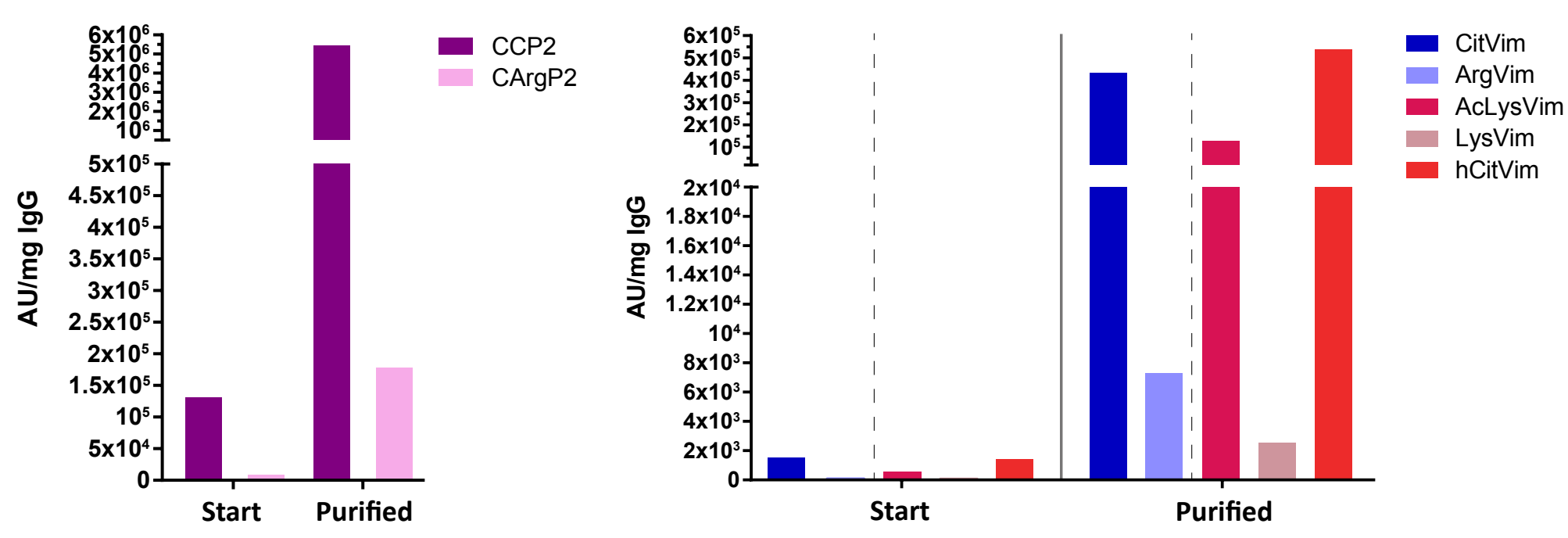

RA7
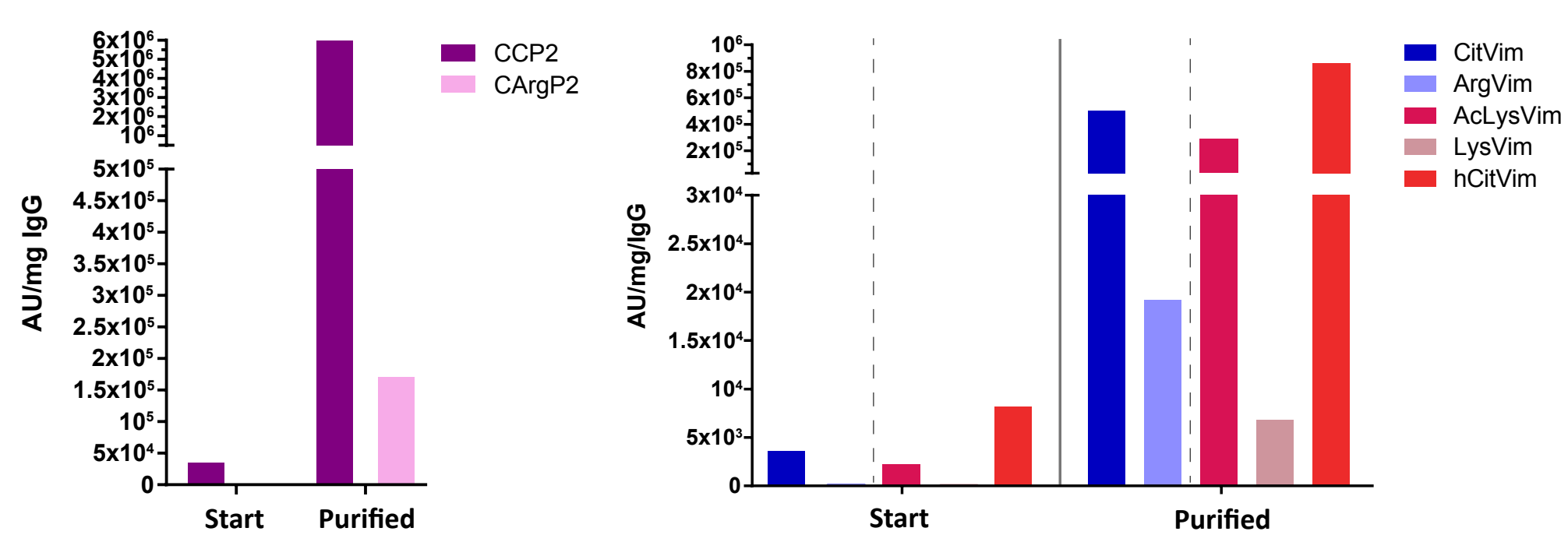

C
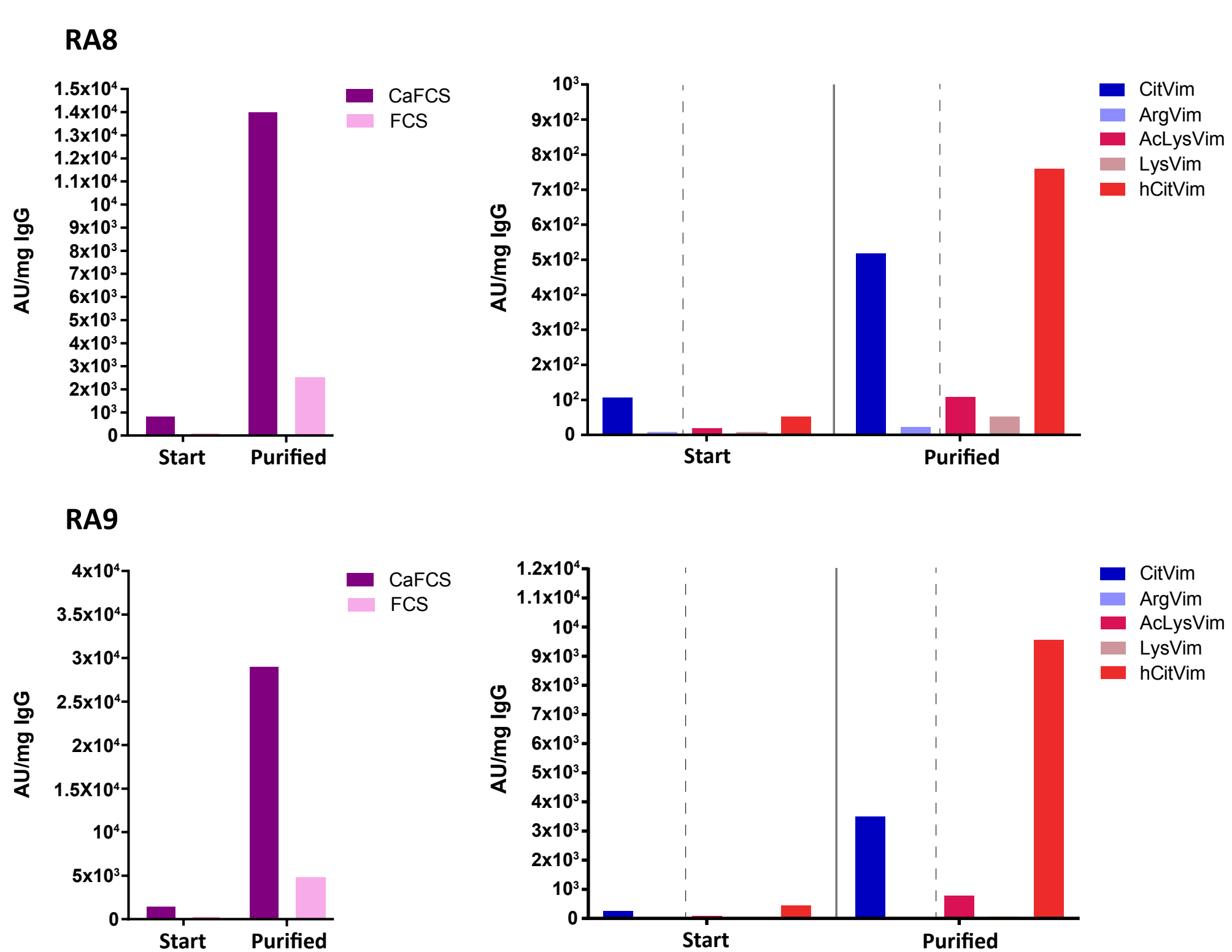


\section{Proteins and modifications}

Mouse albumin was purchased from Merck Millipore (Cat\# 126674), human fibrinogen and chicken ovalbumin (OVA) were purchased from Sigma Aldrich (Cat\# F4883 and Cat\# A5503 respectively). Carbamylation of proteins was achieved by incubating the proteins with potassium cyanate (Cat\# 215074, Sigma Aldrich) as has been described before [1]. In short, OVA and mouse albumin were incubated overnight at $37^{\circ} \mathrm{C}$ in an end concentration of $1 \mathrm{M}$ potassium cyanate at a protein concentration ranging between 1 and $5 \mathrm{mg} / \mathrm{mL}$. Human fibrinogen was incubated in $0.5 \mathrm{M}$ potassium cyanate for 3 days at $4^{\circ} \mathrm{C}$. All proteins were subsequently extensively dialysed in PBS for 3 days. Acetylation was performed as previously described [2]. In short, proteins were diluted to a concentration of $1 \mathrm{mg} / \mathrm{mL}$ in $0.1 \mathrm{M} \mathrm{Na}_{2} \mathrm{CO}_{3}$. Per $20 \mathrm{~mL}$ of protein solution, $100 \mathrm{uL}$ of acetic anhydride was added and subsequently $400 \mathrm{uL}$ of pyridine. Proteins were incubated at $30^{\circ} \mathrm{C}$ for 5 hours or overnight whilst shaking. After incubation, the acetylation reaction was stopped by adding $400 \mathrm{uL}$ (per $20 \mathrm{~mL}$ solution) of $1 \mathrm{M}$ Tris. Acetylated proteins were purified by exchanging the buffer for PBS through Zeba Spin Desalting columns (Thermo Scientific). Citrullination of OVA and fibrinogen was performed by incubation of the proteins with PeptidylArginine Deiminase (PAD) 4 enzyme (Cat\# 1584, Sigma Aldrich) in the presence of $0.1 \mathrm{M}$ Tris- $\mathrm{HCl}\left(\mathrm{pH} \mathrm{7.6)}\right.$ and $0.15 \mathrm{M} \mathrm{CaCl}_{2}$. For OVA, 3 units of PAD were added per $\mathrm{mg}$ of protein for the citrullination process whereas for fibrinogen $5 \mathrm{U}$ PAD per mg protein was used. Both proteins are incubated overnight at $53^{\circ} \mathrm{C}$. Modifications were validated by ELISA as described in the supplementary materials and methods.

ELISA modified antigens

Modification of fibrinogen and OVA were validated by ELISAs using commercial polyclonal rabbit anticarbamyl-lysine antibodies (Cat\# STA-078, Cell Biolabs) and commercial polyclonal rabbit antiacetylated-lysine antibodies (Cat\# ADI-KAP-TF120-E, Enzo Lifesciences), or our human ACPA monoclonal antibody as described in [3]. In short, proteins were coated at a concentration of $10 \mu \mathrm{g} / \mathrm{mL}$ (in 0.1M carbonatebicarbonate buffer, $\mathrm{pH}$ 9.6) on Nunc Maxisorp plates (Cat\# 430341, Thermofisher Scientific) and incubated overnight at $4^{\circ} \mathrm{C}$. Wells were blocked with PBS $+2 \%$ BSA to inhibit unspecific antibody binding to the plastic for 4 hours at $4^{\circ} \mathrm{C}$ before incubating the plates with the anti-carbamyllysine antibodies, anti-acetylated-lysine antibodies or the ACPA monoclonal (diluted in RIA buffer containing $10 \mathrm{mM}$ TRIS ( $\mathrm{pH} 7.6$ ), $350 \mathrm{mM} \mathrm{NaCl}, 1 \%$ TritonX, $0.5 \%$ Na-deoxycholate and $0.1 \%$ SDS) overnight at $4^{\circ} \mathrm{C}$. Binding of the antibodies was detected by a goat-anti-rabbit Horse RadishPeroxidase (HRP)-conjugated antibody (for the rabbit polyclonal antibodies) (\#P0448, DAKO) or a rabbit-antihuman-IgG HRP-conjugated antibody (for the human ACPA monoclonal) (Cat\# P0214, DAKO) (4hrs at $4^{\circ} \mathrm{C}$ or $2 \mathrm{hrs}$ at RT). HRP content was visualised by incubation with ABTS (2,2'-azino-bis(3ethylbenzothiazoline-6-sulphonic acid)) with 1:2000 H2O2. Fibrinogen nor OVA was recognised by commercial antibodies against either carbamylated or acetylated lysine, indicating the absence of PTMs (Fig S1B). PAGE (NuPAGE Bis-Tris Precast Gel, Life Technologies). Bands were cut from the gel, and the proteins subjected to reduction with dithiothreitol, alkylation with iodoacetamide and in-gel trypsin digestion using Proteineer DP digestion robot (Bruker). 
Tryptic peptides were extracted from the gel slices, lyophilized, dissolved in 95/3/0.1 v/v/v water/acetonitril/formic acid and subsequently analysed by on-line C18 nanoHPLC MS/MS with a system consisting of an Easy nLC 1000 gradient HPLC system (Thermo, Bremen, Germany), and a LUMOS mass spectrometer (Thermo). Fractions were injected onto a homemade precolumn (100 $\mu \mathrm{m}$ $\times 15 \mathrm{~mm}$; Reprosil-Pur C18-AQ $3 \mu \mathrm{m}$, Dr. Maisch, Ammerbuch, Germany) and eluted via a homemade analytical nano-HPLC column ( $15 \mathrm{~cm} \times 50 \mu \mathrm{m}$; Reprosil-Pur C18-AQ $3 \mathrm{um})$. The gradient was run from $10 \%$ to $40 \%$ solvent $B(20 / 80 / 0.1$ water/acetonitrile/formic acid (FA) v/v/v) in 20 min. The nano-HPLC column was drawn to a tip of $\sim 5 \mu \mathrm{m}$, and acted as the electrospray needle of the MS source. The LUMOS mass spectrometer was operated in data-dependent MS/MS (top-10 mode) with collision energy at $32 \mathrm{~V}$ and recording of the MS2 spectrum in the orbitrap. In the master scan (MS1) the resolution was 120,000, the scan range 400-1500, at an AGC target of 400,000 @ maximum fill time of $50 \mathrm{~ms}$. Dynamic exclusion after $\mathrm{n}=1$ with exclusion duration of $10 \mathrm{~s}$. Charge states 2-5 were included. For MS2 precursors were isolated with the quadrupole with an isolation width of $1.2 \mathrm{Da}$. HCD collision energy was set to $32 \mathrm{~V}$. First mass was set to $110 \mathrm{Da}$. The MS2 scan resolution was 30,000 with an AGC target of 50,000@maximum fill time of 60 ms.

In a post-analysis process, raw data were first converted to peak lists using Proteome Discoverer version 2.1 (Thermo Electron), and then submitted to the Uniprot database (452772 entries), using Mascot v. 2.2.04 (www.matrixscience.com) for protein identification. Mascot searches were with 10 ppm and 0.02 Da deviation for precursor and fragment mass, respectively, and trypsin as enzyme. Up to two missed cleavages were allowed, and carbamidomethyl on Cys was set as a fixed modification. Methionine oxidation, carbamylation (Lys) and acetylation (Lys) were set as variable modification. Protein modifications were finally compared using Scaffold software version 4.7.5 (www.proteomesoftware.com). The interpretation of MS2 spectra of modified peptides were also manually judged. Abundances were estimated using Proteome Discoverer workflow. The mass spectrometry proteomics data have been deposited to the ProteomeXchange Consortium via the PRIDE [4] partner repository with the dataset identifier PXD012898.

\section{Mouse immunisations}

8-10 week-old female C57BL6/J mice were purchased from Charles River. Mice received two injections intraperitoneal with antigen $(100 \mu \mathrm{g})$ emulsified in Alhydrogel (Cat\# vac-alu-250, Invivogen) in a 1:1 ratio. Animal experiments were approved by the local Ethical Committee for Animal Experimentation and performed conform national guidelines. All immunised mice were healthy and showed no signs of autoimmunity throughout the experiment.

\section{Legends supplementary figures}

\section{Supplementary figure 1:}

\section{Structural overview of the posttranslational protein modifications}

Schematic view of the amino acid structures of arginine and lysine, and their conversions towards citrulline, homocitrulline and acetylated lysine (A). ELISA with commercial polyclonal anti-acetylatedlysine antibodies, polyclonal anti-carbamylated-lysine antibodies or monoclonal ACPA to test modified proteins for the presence of post-translational modifications (B). Non-modified OVA nor fibrinogen is recognised by the commercial antibodies or the ACPA-monoclonal. OVA, ovalbumin; Fib, fibrinogen; 
Ca, carbamylated; Cit, citrullinated; Ac, acetylated; OD, optical density; PAD, peptidylarginine deiminase; ACPA, anti-citrullinated-protein antibodies; ug/mL, microgram per milliliter.

\section{Supplementary figure 2:}

\section{Immunisation with CaOVA or AcOVA induces antibody responses towards modified MBP.}

Antibody reactivity towards modified MBP in sera derived from non-immunised (A), OVA-immunised (B), CitOVA-immunised (C), CaOVA-immunised (D) or AcOVA-immunised (E) mice was measured by ELISA. Reactivity is depicted as OD values measured at $415 \mathrm{~nm}$. For all groups, $n=6$. Representative data from two experiments is shown. OVA, ovalbumin; Cit, citrullinated; $\mathrm{Ca}$, carbamylated; $\mathrm{Ac}$, acetylated; MBP, myelin basic protein; OD, optical density.

Supplementary figure 3:

\section{Flow-through of CCP2-specific antibody purification renders low levels of CCP2-reactivity}

The flow-through after CCP2-specific antibody purification from synovial fluid (A) or plasma (B) contains low levels of antibody reactivity towards the CCP2 peptide. Two representative RA patients are shown for the CCP2 isolation. Similar results have been acquired for the Ca-FCS-specific purifications. Reactivity is shown as arbitrary units per mg IgG. CCP2, cyclic citrullinated peptide 2; CArgP2, cyclic arginine-control peptide 2, AU, arbitrary units; mg, milligram; IgG, immunoglobulin $\mathrm{G}$

1. Shi J, Knevel R, Suwannalai P, van der Linden MP, Janssen GM, van Veelen PA, et al. Autoantibodies recognizing carbamylated proteins are present in sera of patients with rheumatoid arthritis and predict joint damage. Proc Natl Acad Sci U S A. 2011 Oct 18; 108(42):17372-17377. 2. Guan KL, Yu W, Lin Y, Xiong Y, Zhao S. Generation of acetyllysine antibodies and affinity enrichment of acetylated peptides. Nat Protoc. 2010 Sep; 5(9):1583-1595.

3. Verheul MK, van Veelen PA, van Delft MAM, de Ru A, Janssen GMC, Rispens T, et al. Pitfalls in the detection of citrullination and carbamylation. Autoimmun Rev. 2018 Feb; 17(2):136-141.

4. Perez-Riverol Y, Csordas A, Bai J, Bernal-Llinares M, Hewapathirana S, Kundu DJ, et al. The PRIDE database and related tools and resources in 2019: improving support for quantification data. Nucleic Acids Res. 2019 Jan 8; 47(D1):D442-D450. 
A

$$
{ }_{\text {Arginine }}^{\Gamma} \underset{\mathrm{NH}_{2}}{\mathrm{NH}} \stackrel{\mathrm{C}}{\mathrm{C}} \frac{\mathrm{I}}{\mathrm{NH}}-\underset{\mathrm{CH}_{2}}{\mathrm{C}} \mathrm{CH}_{2}-\mathrm{CH}_{2} \frac{\xi}{\xi}
$$

$$
\mathrm{NH}_{2} \frac{1}{\rfloor} \mathrm{CH}_{2}-\mathrm{CH}_{2}-\mathrm{CH}_{2}-\mathrm{CH}_{2} \frac{\xi}{\xi}
$$

Lysine

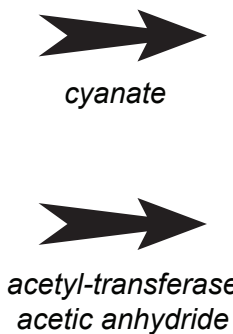

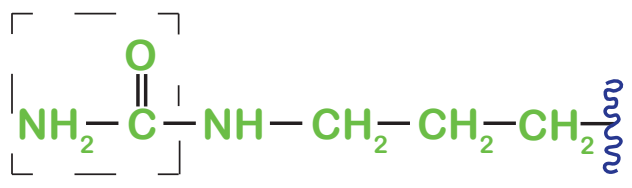

Citrulline<smiles>CCCCCNC(N)=O</smiles>

$\ulcorner-\neg \quad$ Homocitrulline

$\mathrm{CH}_{3}-\stackrel{\mathrm{O}}{\mathrm{C}} \frac{\mathrm{I}}{\mathrm{N}} \mathrm{NH}-\mathrm{CH}_{2}-\mathrm{CH}_{2}-\mathrm{CH}_{2}-\mathrm{CH}_{2} \frac{\xi}{\xi}$

Acetyl-lysine

B

Anti-carbamylated lysine antibody

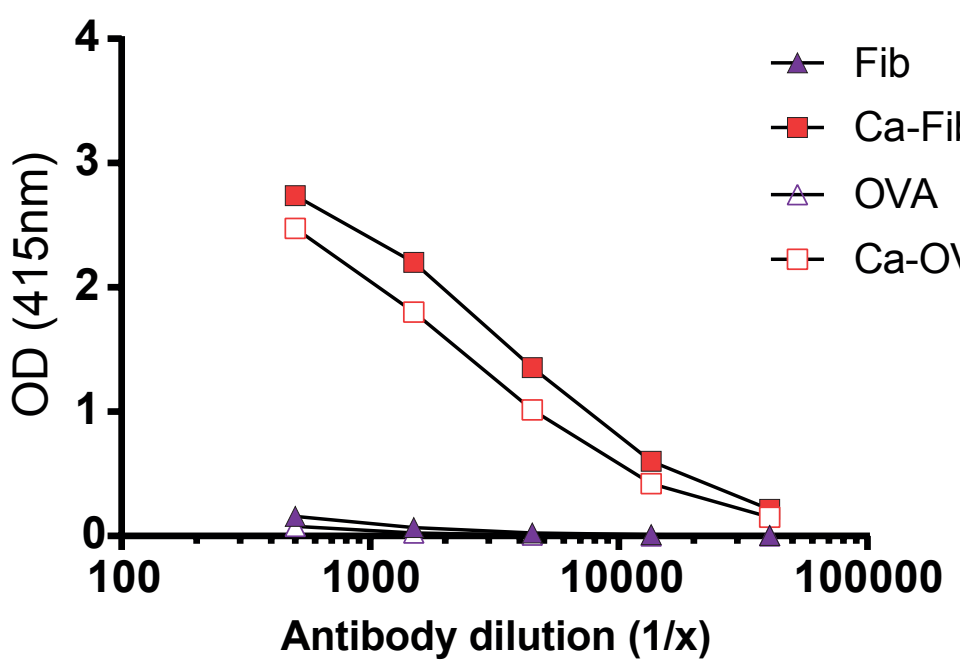

Monoclonal ACPA

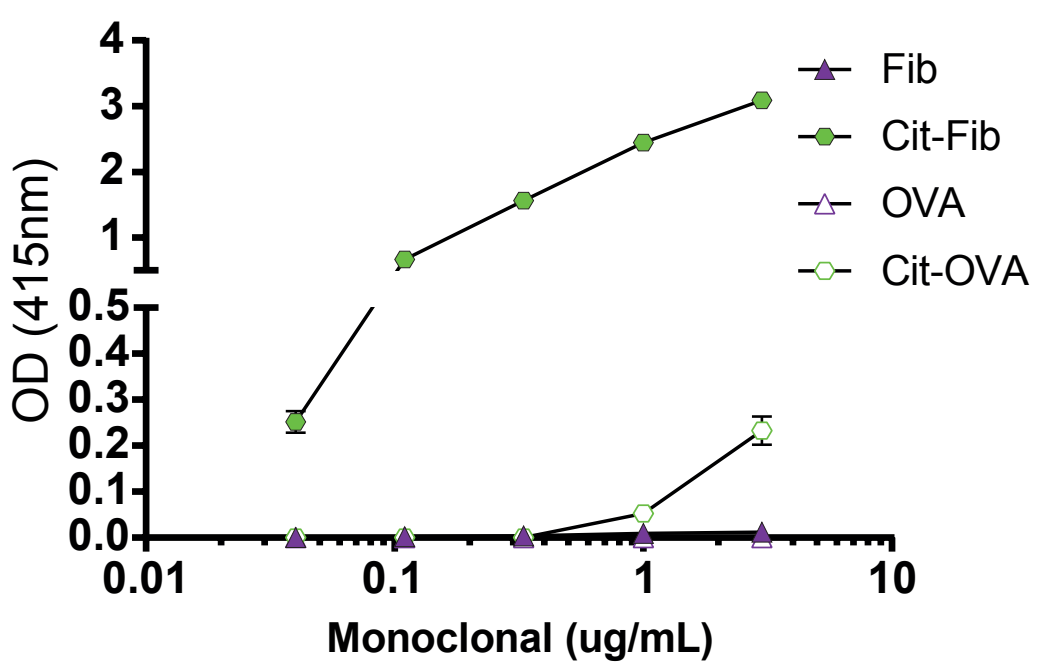

Anti-acetylated lysine antibody

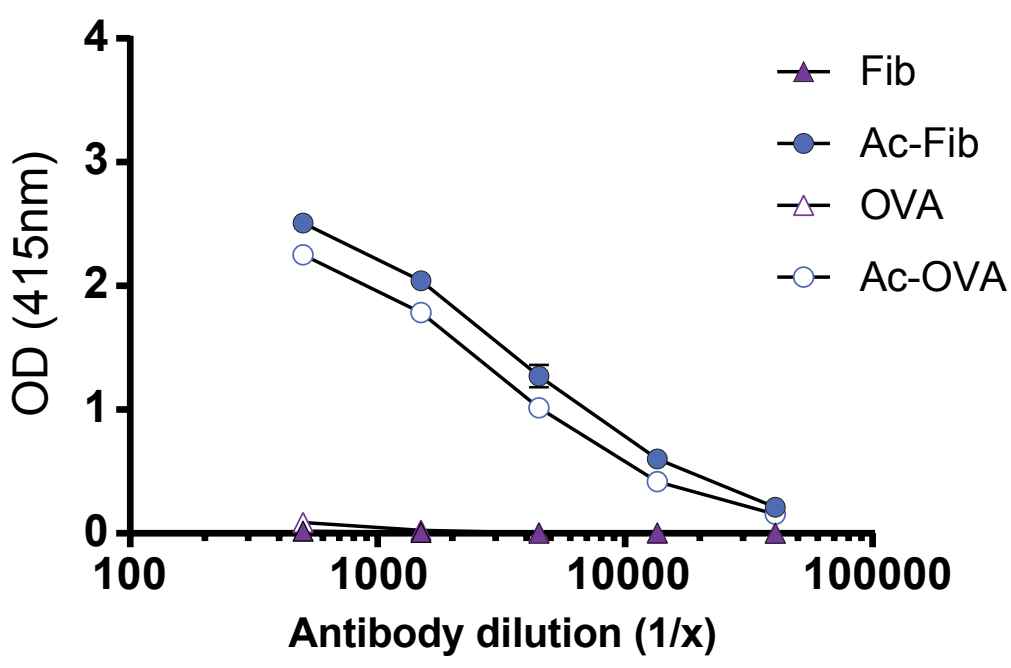


A

Non-immunised mice

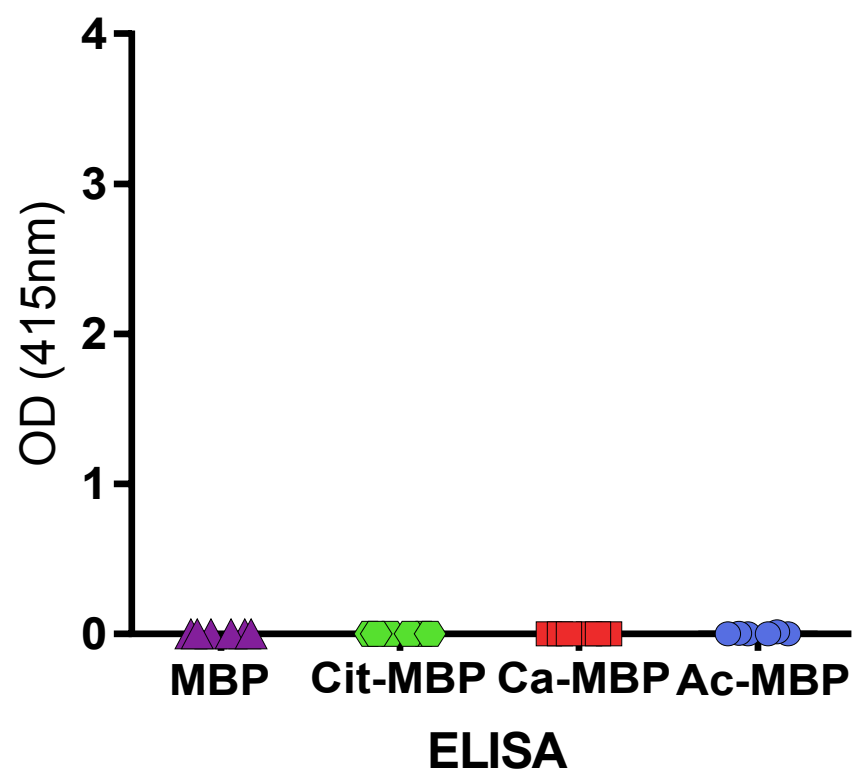

C

Cit-OVA-immunised mice

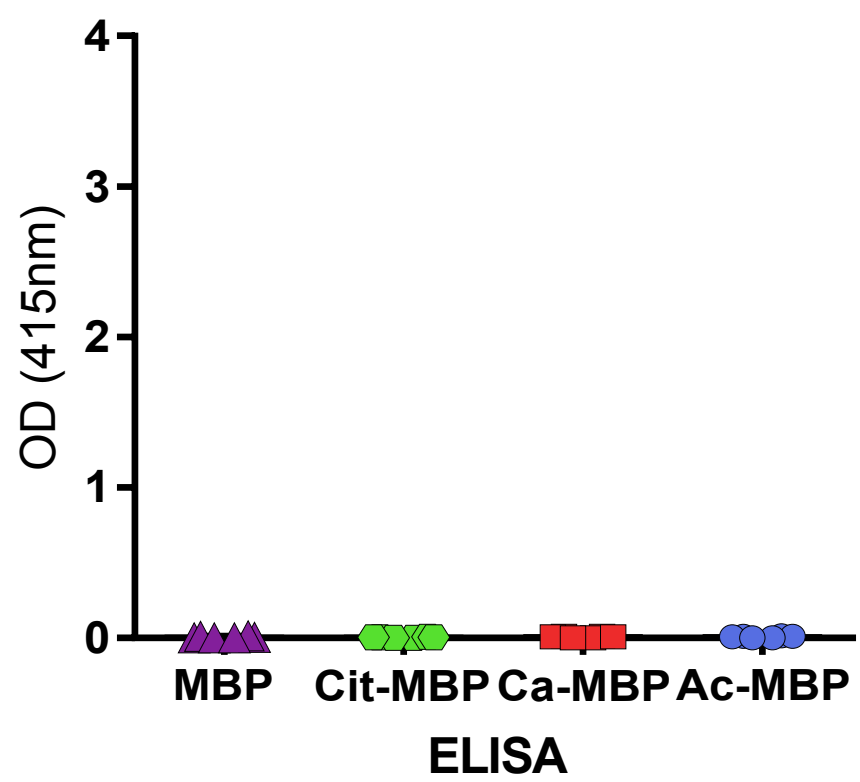

E

Ac-OVA-immunised mice

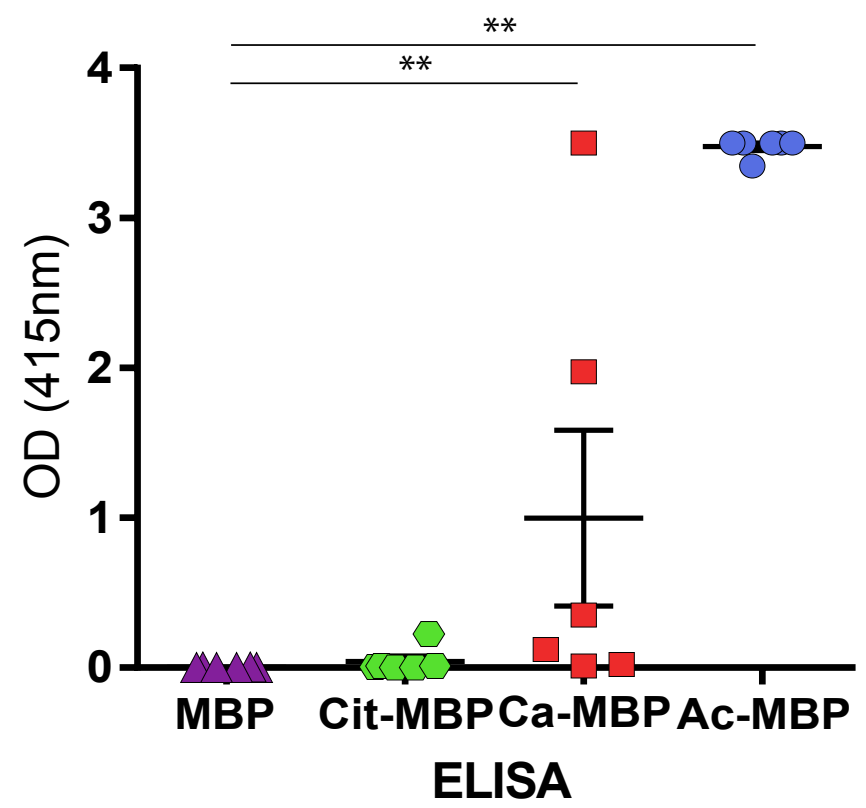

B

OVA-immunised mice

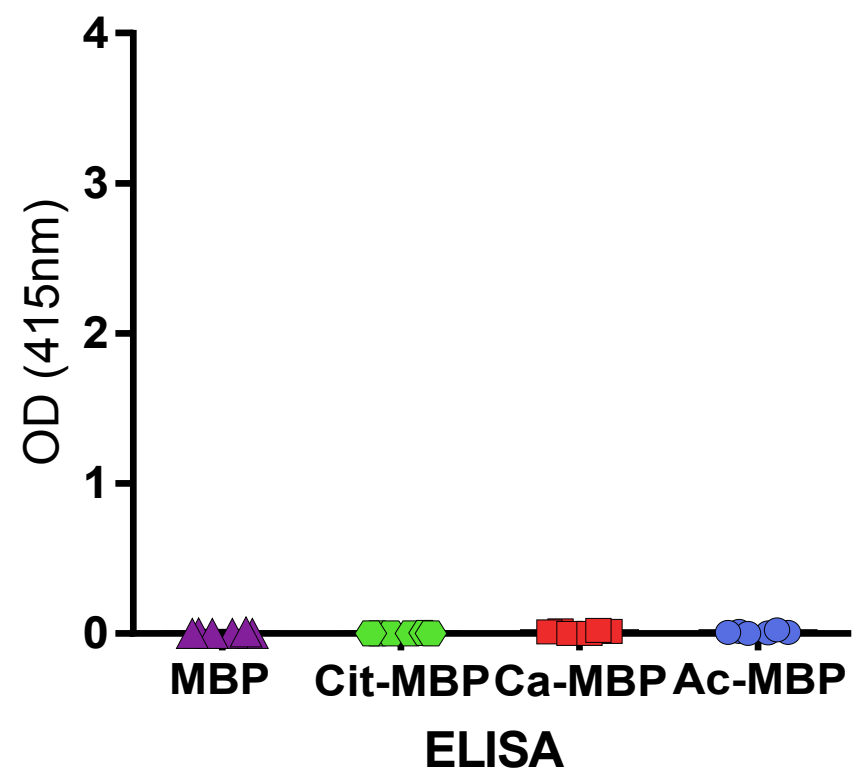

D

Ca-OVA-immunised mice

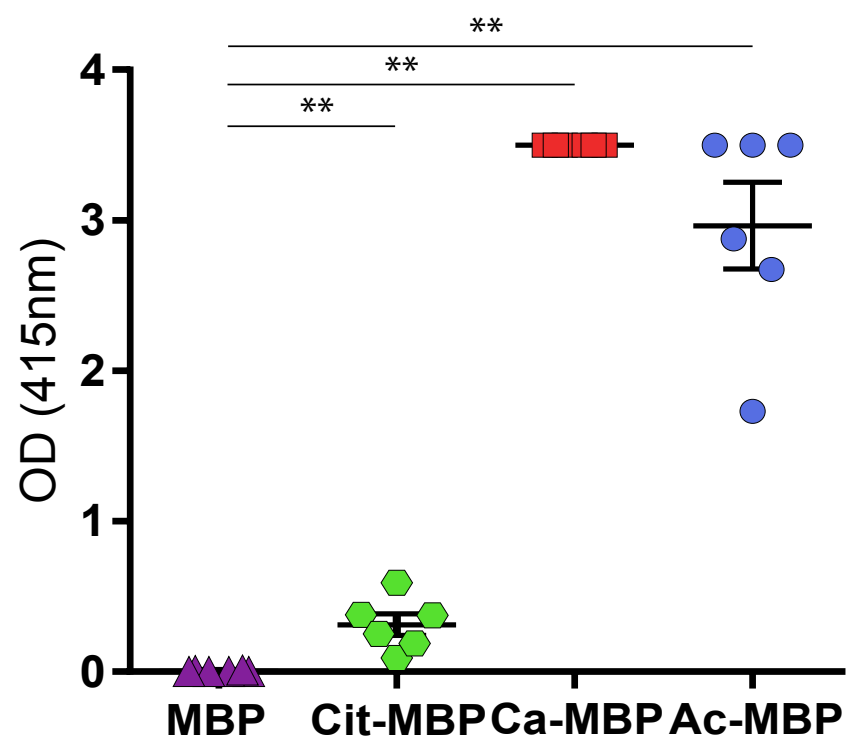

ELISA 
A

RA4

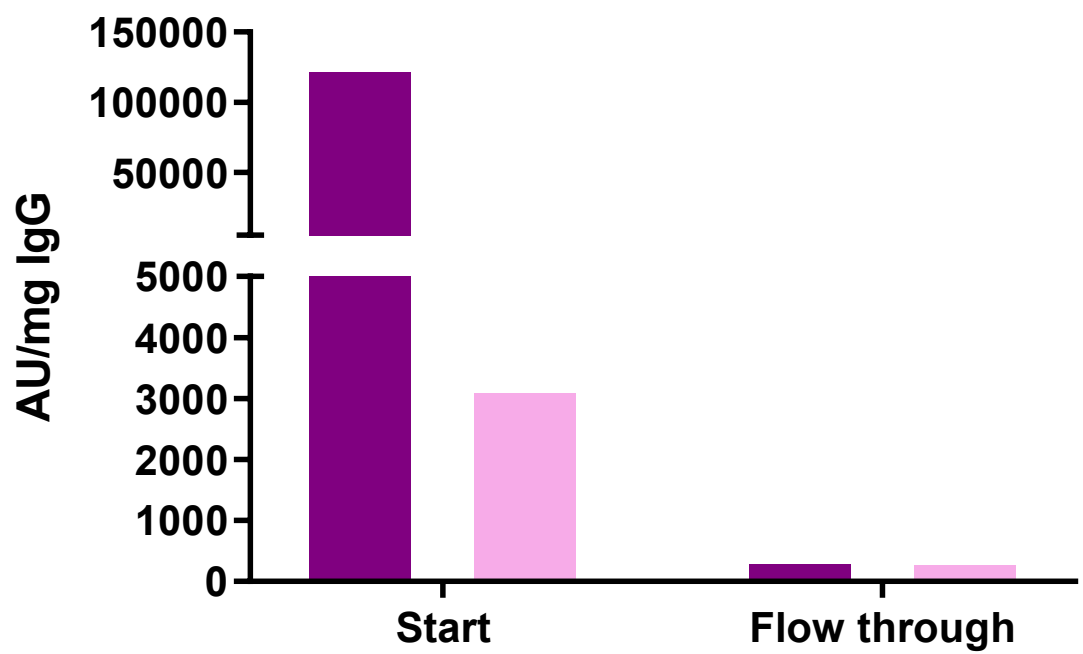

B

RA6

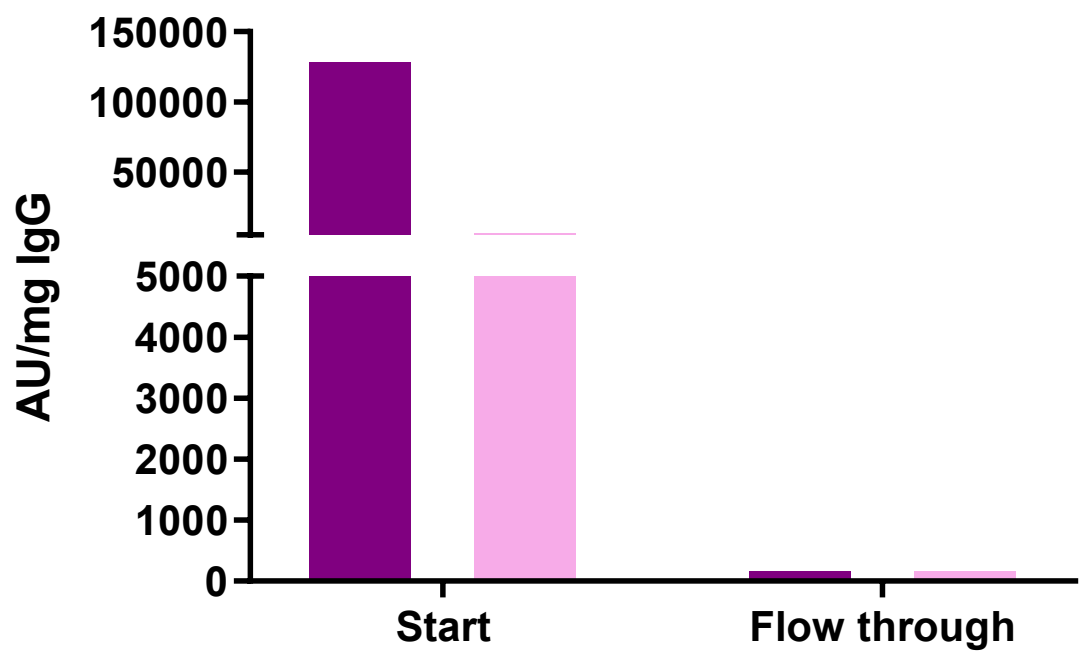

CCP2

CArgP2 